Portland State University

PDXScholar

Fall 12-1-2016

\title{
Surviving Catastrophe: Resource Allocation and Plant Interactions Among the Mosses of Mount St. Helens Volcano
}

Trevor David Williams

Portland State University

Follow this and additional works at: https://pdxscholar.library.pdx.edu/open_access_etds

Part of the Biology Commons, and the Plants Commons Let us know how access to this document benefits you.

\section{Recommended Citation}

Williams, Trevor David, "Surviving Catastrophe: Resource Allocation and Plant Interactions Among the Mosses of Mount St. Helens Volcano" (2016). Dissertations and Theses. Paper 3373.

https://doi.org/10.15760/etd.5264

This Thesis is brought to you for free and open access. It has been accepted for inclusion in Dissertations and Theses by an authorized administrator of PDXScholar. Please contact us if we can make this document more accessible: pdxscholar@pdx.edu. 


\section{Surviving Catastrophe:}

Resource Allocation and Plant Interactions

Among the Mosses of Mount St. Helens Volcano

\section{by}

Trevor D. Williams

A thesis submitted in partial fulfillment of the requirements for the degree of
Master of Science
in
Biology
Thesis Committee:
Sarah Eppley, chair
Daniel Ballhorn
Radhika Reddy
John Bishop

Portland State University

2016 


\begin{abstract}
Mosses are some of the first colonizers to disturbed sites, yet their roles in early plant community structuring are not well understood. The primary succession zones of volcanoes provide opportunities to conduct natural experiments into how mosses contribute to early plant community formation, as well as how the unique environments found in such zones affect plant traits, particularly those associated with stress tolerance. Though plant community changes have been well-documented since Mount St. Helens (MSH) volcano erupted in 1980, the volcano's moss assemblages, their influence on other plants, and their potential roles in chemical-mediated competition and biogeochemical cycling have garnered little attention. Using a natural stress gradient from primary to secondary succession zones on $\mathrm{MSH}$, and in control and nutrient manipulated test plots, I sought to elucidate how populations of three dominant moss species, Polytrichum juniperinum, Ceratodon purpureus, and Racomitrium canescens, respond to abiotic stress, as well as to provide life history and interaction data on establishment stages of these stress tolerant taxa.
\end{abstract}

I first analyzed possible tradeoffs in survival strategies of four moss communities in test plots along an abiotic stress gradient. In P. juniperinum, seta specific density $(\mathrm{mg} / \mathrm{mm})$ increased significantly in response to nitrogen $(\mathrm{N})$ addition. Differences in both vegetative and sexual reproductive morphological measurements were dependent on site and did not correlate with abiotic stress. In C. purpureus, the percentage of total spores germinated increased with $\mathrm{N}$ addition. Site dependent responses in nutrient allocation to 
vegetative and reproductive structures may be a result of phenotypic plasticity alone or may be a result of local adaptation. In mosses adapted to environmental stress, the allocation of nitrogen must be balanced between growth and survival. Efficient nitrogen uptake confers a competitive advantage if allocated to the higher dispersal of quickly germinating spores.

Second, my results show the moss $R$. canescens may be able to inhibit the germination rate of co-occurring moss spores when spores were germinated in moss gametophyte infusions. $R$. canescens may also inhibit the germination of the co-occurring vascular plant Lupinus lepidus when seeds were germinated within intact moss patches. By uncovering chemical-mediated interactions between mosses on the germination and initial growth of neighboring mosses and vascular plants we can gain a better understanding of the mechanisms stress tolerant plants may use to limit resource competition. Such advantages offer insight into how mosses effectively colonize and affect primary succession landscapes. 


\section{TABLE OF CONTENTS}

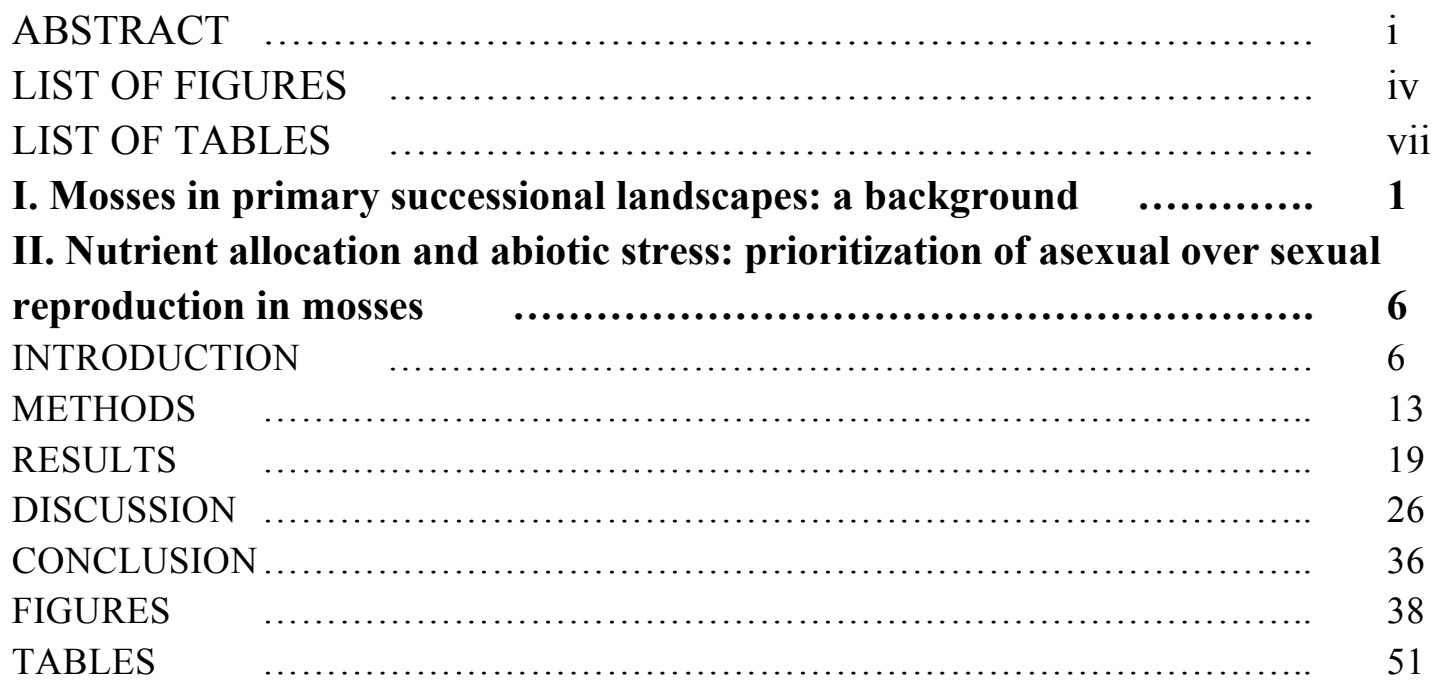

III. Chemical inhibition of germination by mosses $\quad$................. $\quad 52$

INTRODUCTION $\quad$................................................. 52

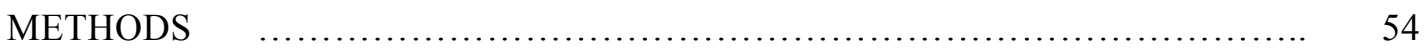

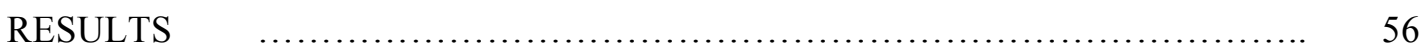

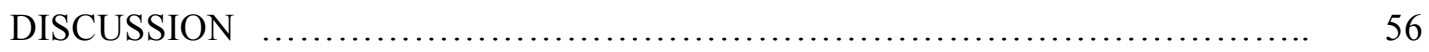

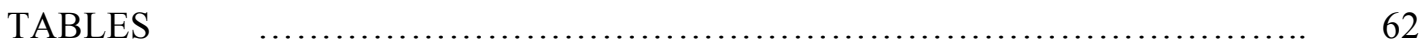

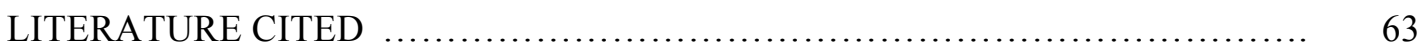




\section{LIST OF FIGURES}

Figure 1.

Least squared means ( \pm standard error) of gametophyte length $(\mathrm{mm})$ of $P$. juniperinum based on full model comparing site (primary succession sites West and East; secondary succession sites Harmony and Norway), treatment (nitrogen addition VS control) and interaction between the two variables $(\mathrm{DF}=5 ; \mathrm{F}=3.9982 ; \mathrm{P}=0.0021)$. A) Effect test results from site only $(\mathrm{DF}=2 ; \mathrm{F}=6.8981 ; \mathrm{P}=0.0014)$ and $\mathrm{B})$ results from interaction $(\mathrm{DF}=2$; $\mathrm{F}=3.6634 ; \mathrm{P}=0.0283$ ). Levels not connected by same letter are significantly different based on Tukey's HSD.

Figure 2.

Least squared means ( \pm standard error) of gametophyte mass $(\mathrm{mg})$ of $P$. juniperinum based on full model comparing site (primary succession sites West and East; secondary succession sites Harmony and Norway), treatment (nitrogen addition VS control) and interaction between the two variables $(\mathrm{DF}=5 ; \mathrm{F}=2.0249 ; \mathrm{P}=0.0793)$. A) Effect test results from site only $(\mathrm{DF}=2 ; \mathrm{F}=4.9368 ; \mathrm{P}=0.0086)$ and $\mathrm{B})$ results from interaction $(\mathrm{DF}=2$; $\mathrm{F}=1.1145 ; \mathrm{P}=0.3312$ ). Levels not connected by same letter are significantly different based on Tukey's HSD.

Figure 3.

Least squared means ( \pm standard error) of gametophyte specific density (GSD; $\mathrm{mg} / \mathrm{mm}$ ) of $P$. juniperinum based on full model comparing site (primary succession sites West and East; secondary succession sites Harmony and Norway), treatment (nitrogen addition VS control) and interaction between the two variables ( $\mathrm{DF}=5 ; \mathrm{F}=2.5189 ; \mathrm{P}=0.0327)$. A) Effect test results from site only $(\mathrm{DF}=2 ; \mathrm{F}=1.8983 ; \mathrm{P}=0.154)$ and $\mathrm{B})$ results from interaction $(\mathrm{DF}=2 ; \mathrm{F}=0.4447 ; \mathrm{P}=0.642)$. Levels not connected by same letter are significantly different based on Tukey's HSD.

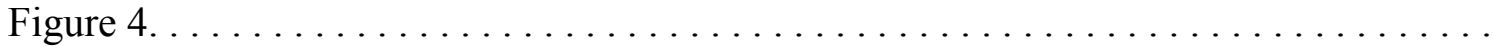
Least squared means ( \pm standard error) of calyptra mass $(\mathrm{mg})$ of $P$. juniperinum based on full model comparing site (primary succession sites West and East; secondary succession sites Harmony and Norway), treatment (nitrogen addition VS control) and interaction between the two variables $(\mathrm{DF}=5 ; \mathrm{F}=4.6982 ; \mathrm{P}=0.0006)$. A) Effect test results from site only $(\mathrm{DF}=2 ; \mathrm{F}=6.9085 ; \mathrm{P}=0.0014)$ and $\mathrm{B})$ results from interaction $(\mathrm{DF}=2 ; \mathrm{F}=3.0552$; $\mathrm{P}=0.05050$ ). Levels not connected by same letter are significantly different based on Tukey's HSD.

Figure 5. . .

Least squared means ( \pm standard error) of seta length $(\mathrm{mm})$ of $P$. juniperinum based on full model comparing site (primary succession sites West and East; secondary succession sites Harmony and Norway), treatment (nitrogen addition VS control) and interaction between the two variables $(\mathrm{DF}=5 ; \mathrm{F}=6.5108 ; \mathrm{P}<0.0001)$. A) Effect test results from site only $(\mathrm{DF}=2 ; \mathrm{F}=15.8537 ; \mathrm{P}<.0001)$ and $\mathrm{B})$ results from interaction $(\mathrm{DF}=2 ; \mathrm{F}=4.3255$; 
$\mathrm{P}=0.0152$ ). Levels not connected by same letter are significantly different based on Tukey's HSD.

Figure 6.

Least squared means ( \pm standard error) of seta mass $(\mathrm{mg})$ of $P$. juniperinum based on full model comparing site (primary succession sites West and East; secondary succession sites Harmony and Norway), treatment (nitrogen addition VS control) and interaction between the two variables $(\mathrm{DF}=5 ; \mathrm{F}=6.5108 ; \mathrm{P}<0.0001)$. A) Effect test results from site only $(\mathrm{DF}=2 ; \mathrm{F}=15.8537 ; \mathrm{P}<.0001)$ and $\mathrm{B})$ results from interaction $(\mathrm{DF}=2 ; \mathrm{F}=4.3255$; $\mathrm{P}=0.0152$ ). Levels not connected by same letter are significantly different based on Tukey's HSD.

Figure 7

Least squared means ( \pm standard error) of seta specific density (SSD; mg/mm) of $P$. juniperinum based on full model comparing site (primary succession sites West and East; secondary succession sites Harmony and Norway), treatment (nitrogen addition VS control) and interaction between the two variables $(\mathrm{DF}=5 ; \mathrm{F}=6.8894 ; \mathrm{P}<0.0001)$. A) Effect test results from site only $(\mathrm{DF}=2 ; \mathrm{F}=2.0846 ; \mathrm{P}<.0001)$ and $\mathrm{B})$ results from nitrogen treatment $(\mathrm{DF}=1 ; \mathrm{F}=9.8117 ; \mathrm{P}=0.00210)$ and interaction $(\mathrm{DF}=2 ; \mathrm{F}=0.4399 ; \mathrm{P}=0.64514)$. Levels not connected by same letter are significantly different based on Tukey's HSD.

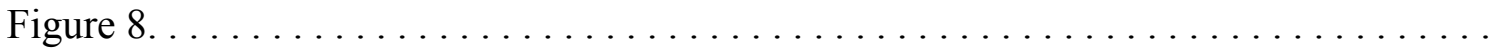
Least squared means ( \pm standard error) of capsule mass $(\mathrm{mg})$ of $P$. juniperinum based on full model comparing site (primary succession sites West and East; secondary succession sites Harmony and Norway), treatment (nitrogen addition VS control) and interaction between the two variables $(\mathrm{DF}=5 ; \mathrm{F}=4.8407 ; \mathrm{P}=0.0004)$. A) Effect test results from site only $(\mathrm{DF}=2 ; \mathrm{F}=10.9416 ; \mathrm{P}<0.0001)$ and $\mathrm{B})$ results from nitrogen treatment $(\mathrm{DF}=2 ; \mathrm{F}=$ $0.9215 ; \mathrm{P}=0.3389)$ and interaction $(\mathrm{DF}=2 ; \mathrm{F}=1.2621 ; \mathrm{P}=0.28650)$. Levels not connected by same letter are significantly different based on Tukey's HSD.

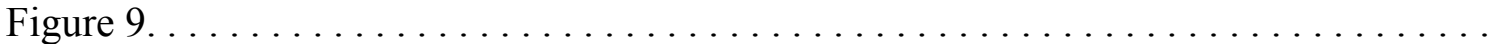
Least squared means ( \pm standard error) of total sporophyte mass $(\mathrm{mg})$ of $P$. juniperinum based on full model comparing site (primary succession sites West and East; secondary succession sites Harmony and Norway), treatment (nitrogen addition VS control) and interaction between the two variables $(\mathrm{DF}=5 ; \mathrm{F}=4.8407 ; \mathrm{P}=0.0004)$. A) Effect test results from site only $(\mathrm{DF}=2 ; \mathrm{F}=10.9416 ; \mathrm{P}<0.0001)$ and $\mathrm{B})$ results from nitrogen treatment $(\mathrm{DF}=2 ; \mathrm{F}=0.9215 ; \mathrm{P}=0.3389)$ and interaction $(\mathrm{DF}=2 ; \mathrm{F}=1.2621 ; \mathrm{P}=0.28650)$. Levels not connected by same letter are significantly different based on Tukey's HSD.

Figure 10.

Least squared means ( \pm standard error) of $A)$ maximum spore germination as a percent of the total count and B) total spore count per capsule of $P$. juniperinum by site (primary succession sites West and East; secondary succession sites Harmony and Norway). Levels not connected by same letter are significantly different based on Tukey's HSD. 
Figure 11

Least squared means ( \pm standard error) of total sporophyte mass $(\mathrm{mg})$ of C. purpureus based on full model comparing site (primary succession sites West and East; secondary succession sites Harmony and Norway), treatment (nitrogen addition VS control) and interaction between the two variables $(\mathrm{DF}=5 ; \mathrm{F}=4.8407 ; \mathrm{P}=0.0004)$. A) Effect test results from site only $(\mathrm{DF}=2 ; \mathrm{F}=0.0149 ; \mathrm{P}=0.6763)$ and $\mathrm{B})$ results from nitrogen treatment $(\mathrm{DF}=2 ; \mathrm{F}=1.7349 ; \mathrm{P}=0.1792)$ and interaction $(\mathrm{DF}=2 ; \mathrm{F}=0.1518 ; \mathrm{P}=0.8593)$. Levels not connected by same letter are significantly different based on Tukey's HSD.

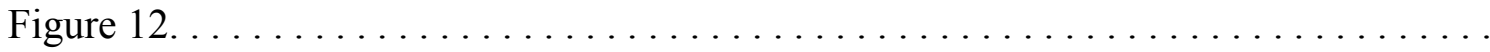
Least squared means ( \pm standard error) of $A)$ maximum spore germination count and $B$ ) total spore count per capsule of $C$. purpureus by site (primary succession sites West and East; secondary succession sites Harmony and Norway). Levels not connected by same letter are significantly different based on Tukey's HSD.

Figure 13.

Least squared means ( \pm standard error) of arcsine transformed data of A) P. juniperinum and B) C. purpureus $\%$ of total spores germinated per day by site (primary succession sites West and East; secondary succession sites Harmony and Norway).

Figure 14

Least squared means ( \pm standard error) of arcsine transformed data of $C$. purpureus $\%$ of total spores germinated per day by plot treatment

Figure 15.

Least squared means ( \pm standard error) of arcsine transformed data of A) C. purpureus and B) $P$. juniperinum $\%$ of total spores germinated per day by treatment (control and infusions of $P$. juniperinum and $R$. canescens.)

Figure 16.

Mean ( \pm standard error) of Lupinus lepidus morphological measurements of seedlings germinated in moss patches and on bare pumice: A) Total seedling dry mass, B) Total seedling length, C) Number of true leaves, and D) Number of rootlets. 


\section{LIST OF TABLES}

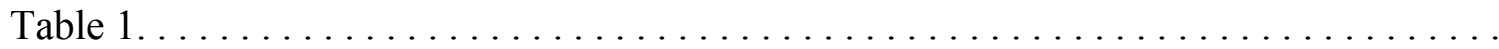

The effects of environment (four sites), nitrogen treatment (treatment versus control), and the interaction between site and nitrogen treatment on morphological response in two moss species using ANOVA. Significant results in bold.

Table 2.

Repeated measures MANOVA on \% germination of total spore counts over time, site, Naddition and interaction. F test results unless otherwise noted. Significant results in bold. Table 3: Repeated measures MANOVA on \% germination of total spore counts over time, site and $\mathrm{N}$-addition of spore origin, and infusion treatment. Significant results in bold.

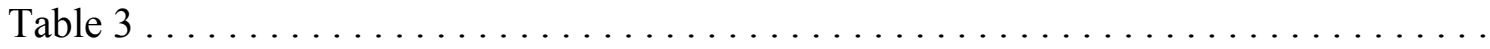

Repeated measures MANOVA on \% germination of total spore counts over time, site and $\mathrm{N}$-addition of spore origin, and infusion treatment. Significant results in bold. 
I. Mosses in primary successional landscapes: a background

Succession - the dynamic interplay of plant species as they inherit the landscape from one another - was introduced as a concept in a 1910 address before the Association of American Geographers by Henry C. Cowles, whose plant succession studies on the sand dunes of Lake Michigan were the first of their kind to be conducted in the United States (Cowles 1899). Though his term was new the ideas he conveyed were older (Worster 1977) and with his work Cowles added to a long line of Enlightenment and early modern European thinkers in the study of what he described as "dynamic plant geography" and the "cycles within cycles" of plant succession. The foundations of modern plant ecology - another term Cowles popularized based on the 1895 work Plantesamfund by pioneering Danish botanist Eugen Warming - marked a revolution within biological sciences, and plant sciences in particular, away from Victorian notions of scientific inquiry as the sole purview of collectors and categorizers.

This modern field of scientific inquiry was shaped by the observational and experimental studies of the early $20^{\text {th }}$ century that sought to explain the role of plants in their environment, how and why had they evolved their myriad forms and functions, and how they shaped their environment and interacted with each other. Frederic Clements (1916) who introduced the widely used terms primary and secondary succession to describe the absence or presence of a biological legacy from which new growth emerges put forth the views that disturbed ecosystems were ever marching towards a climax community, not composed of self-serving individuals but rather aiding each other in a super-organism. Cowles deemed these terms as having "no fundamental value" and 
Clements' theories were criticized, most notably by his contemporary Henry Gleason who introduced the species-individualistic concept of plant interaction (Gleason 1917; 1939). Successional mechanisms were classified in the 1970's by Connell and Slatyer (1977) who put forward the terms facilitative, competitive, and tolerant to explain interand intraspecies plant interactions in successional communities, terms which took into account many more environmental variables than had been previously acknowledged including the spatial scale of a disturbance and its intensity. Phillip Grime (1979) proposed an explanation of how plants had evolved such variable life histories, plotting species by their abilities to exist in areas of variable nutrient availability and varying recurrence of disturbance. The traits a particular plant species uses to avoid or tolerate stress were arranged into the strategies Grime labeled ruderal, competitor or stress tolerator plants. The predictive power of Grime's model as to the trajectory of plant succession in ever changing communities remains limited.

During plant succession each newly arrived species to the landscape has the potential to shape that landscape's trajectory by changing soil hydrology and thermal properties (Chapin et al. 1994), primary production and carbon sequestration (Sparrius \& Kooijman 2013), atmospheric nitrogen fixation (St. John et al. 2012), and the facilitation or inhibition of neighboring individuals across all life stages (Callaway \& Walker 1997; Michalet et al. 2011). Disturbed landscapes provide opportunities to study the evolution of traits and strategies plants use to effectively disperse, establish, survive and compete (Sousa 1984; Chapin et al. 1993). Whether such areas are naturally or anthropogenically generated, their recovery depends upon the unique genetic and physiological characteristics of pioneer species (Linhart \& Grant 1996). The variation in phenologies, 
reproductive modes, and functions plants have evolved to avoid stress will affect population- and community-level composition with exponential effects on the biogeochemical cycles of these landscapes (Craine 2009). Volcanic landscapes where life is effectively erased are particularly suited to observational and manipulative experiments on the survival and establishment strategies of early life stage plants (Rejmanek et al. 1982; Vitousek et al. 1983; del Moral \& Wood 1993; St. John et al. 2012; Talbot et al. 2010; Wuermli 1976). By understanding how plant species colonize, interact with each other, and change their environment, we not only gain insight into the evolution of plants on land, but also gain an understanding of species' responses to a changing environment, particularly the emergence of invasiveness and the ability, or lack thereof, of species to move to new ranges (Vitousek et al. 1997; Yelenik \& D'Antonio 2013). In primary successional landscapes, where the ability to retain water and nutrients by soil biota has not yet developed (Schmidt et al. 2008), mosses in particular as early colonizers may potentially change the course of plant community trajectories (Gornall et al. 2011).

\section{Mosses, biogeochemistry and succession}

Mosses (phylum Bryophyta), the most predominant non-vascular plant division, are successful and persistent colonizers of disturbed sites due to their lightweight, winddistributed spores and their ability to revive from stasis after surviving desiccation (Smith and Stark 2014). It was a student of Linnaeus, Isaac Biberg in 1785 who first published descriptions of moss and lichen succession on bare rock (Cowles 1911; Egerton 2007). Since then a number of studies have focused on the ecological role of mosses (Cornelissen et al. 2007; Gornall et al. 2011), including their role in biogeochemical cycling (Porada et al. 2014). It has been estimated that non-vascular photoautotrophs 
including bryophytes account for 7\% of the Earth's terrestrial net primary production by plants (the conversion of atmospheric carbon to terrestrial carbon), and for half of the terrestrial nitrogen fixation (Elbert et al. 2012). Mosses have the ability to quickly absorb deposited nitrogen (Ackermann et al. 2012) and in some cases fix significant levels of nitrogen $\left(2 \mathrm{~kg} \mathrm{~N} \mathrm{ha}^{-1} \mathrm{yr}^{-1}\right)$ by harboring cyanobacteria (DeLuca et al. 2002; DeLuca et al. 2007). Because the high carbon to nitrogen ratios and secondary compound production of mosses resist decomposition - significant pools of nitrogen and carbon can be locked up in moss populations (Turetsky 2003). These properties undoubtedly influence resource pools in landscapes undergoing primary succession.

\section{Mosses on Mount St Helens}

The primary succession zone of Mount St Helens (MSH) volcano in southwestern Washington is an ideal location to explore the role of mosses in primary succession. Plants in the primary succession zone of MSH have been studied since the devastating eruption of 1980, particularly the role of nitrogen-fixing plant species (Titus 2009), herbivory (Bishop et al. 2005, Yang et al. 2011), and the rates at which coniferous forest species are returning and surviving in this severely nutrient and water limited environment (Titus and Bishop 2014; Schoenfelder et al. 2010). More recently three predominant moss species have been noted in surveys of plant recolonization: Racomitrium canescens, Ceratodon purpureus and Polytrichum juniperinum, with cover values up to $12 \%$ (del Moral et al. 2012). Little attention has been given to these species despite their high abundance. The following studies were conducted not only to analyze moss traits response to enviornmental stress, but also to potentially inform future analyses of bryophyte roles in biogeochemistry during primary succession. Each species 
of these three moss has evolved a set of traits and strategies to cope with life in extreme environments. Each may modify developing soils and communities differently. The more we understand moss responses to environmental pressures, the more we will understand their influence on successional trajectories. 


\section{Nutrient allocation and abiotic stress: prioritization of asexual over sexual reproduction in mosses.}

\section{INTRODUCTION}

In plants adapted to environmental extremes strategies to tolerate or avoid stress include morphological and physiological trade-offs (Casper and Jackson 1997). Water stress avoidance strategies in vascular plants include phenological traits (e.g. timing of growth and reproduction relative to water availability; morphological traits (e.g. desiccation resistant seeds and specialized tissues for water storage; and physiological traits (lowering photosynthetic rate or down regulating defensive compounds) (Chapin, Autumn, and Pugmaire 1993). In contrast, a key adaptation in bryophytes is immediate upregulation of metabolism and photosynthesis in response to moisture availability, and equally rapid stasis upon drying (Proctor 2000). This strategy is facilitated by bryophyte morphology, such as simple leaves of only a few cells thick that lack true vascular anatomy or stomata, and poikylohydric water relations, where water is conducted osmotically through tissues and plant hydration is tied inextricably to the humidity of the environment. Indicators or consequences of drought stress in vascular plants, like the upregulation of specific metabolites or cavitation (McDowell et al. 2008), do not occur in bryophytes (Proctor et al. 2007).

As with adaptations to water limitation, under nutrient limitation plants may regulate resource allocation to phenological, morphological or physiological tradeoffs, including higher root length or associated mycorrhizae to optimize nutrient absorption, lowering nutrient requirements as measured by lower concentrations of particular nutrients in plant tissues, or lowering nutrient loss by prioritizing primary production 
over secondary metabolites and resisting herbivory and decomposition (Hermans et al. 2006). Whether trade offs affect fitness has been difficult to ascertain as comparisons must be made across generations. Further teasing apart allocation differences between phenotypic plasticity or genetic differences between individuals or populations adds to the complication. Additionally, plastic traits or genotype $\mathrm{x}$ environment interactions on reproductive strategies may include differential allocation to asexual reproduction over sexual reproduction and therefore any plant trait is ultimately dependent upon those allocations.

Plant reproductive ecology

Plants allocate resources differentially between sexual reproduction, defenses against herbivory, and vegetative growth, which may include asexual reproduction (Bazzaz et al. 1987). Allocation to one will incur a cost to the others though all may be working in tandem depending on genetic and environmental interactions with the ultimate result being a mixture of strategies that increase survival and fitness upon which natural selection has acted (Craine 2009). Many plant species reproduce asexually by establishing clones after physical damage caused by disturbance where a new individual can arise from any plant cell once conditions are favorable (Santamaría 2002). Predominantly asexual organisms may switch to sexual strategies when under stress. Switching from asexual to sexual reproductive strategies offers a potential solution to stress whereby the costs of reproduction are incurred and energy saving is deprioritized by the threat of mortality (Norrell et al. 2014, Morran et al. 2009). Cost of reproduction studies have shown that trade offs exist in sexually reproducing organisms whereby investment in the next generation incurs a negative cost to the current generation 
including mortality in semelparous individuals or decreases in the ability to sustain optimal metabolism in iteroparous individuals (Stearns 1976). In obligate sexual reproducers, or in organisms where sexual reproduction has already been initiated, the costs of allocation to offspring can be minimized in times of resource limitation (Reznick 1985).

Flowering plants are able to shed flowers or embryos in order to reallocate resources in fewer, more viable, or genetically distinct individuals (Stephenson 1981). Similarly in bryophytes, spore number is inversely related to size of spore, an indicator of maternal investment in the success of the individual offspring (Glime 2015). Fruit and seeds, the results of syngamy, compete for resources with neighboring fruits and seeds as well as non-reproductive structures on the same plant, and this competition is released with the addition of limiting nutrients, including nitrogen (Stephenson 1981). Sexual reproduction is favorable as a response to biotic factors (pathogens, competition, herbivory) where differences among individuals is prioritized as density increases, and asexual reproduction is favorable in extreme or unpredictable landscapes (Mishler 1988). Still other hypotheses maintain that in stable environments either asexual or sexual reproduction will be prioritized, leading to reproductive syndromes (loss of one strategy or the other) as occur in a significant proportion of dioicous mosses - where the haploid generation exhibits two sexes. (Mishler 1988). In large-scale successional landscapes the ability to distribute over vast areas in a short amount of time is unique to sexual reproductive strategies and is particular to early successional species. Once established, however, bet-hedging, an investment in both strategies, or prioritization of preservation of resources already invested until environmental conditions improve may favor a 
strategy of delayed sexual reproduction or an asexual reproductive strategy. Both have been observed in stress tolerant, perennial plants (Chapin, Autumn, and Pugmaire 1993).

Mosses have been used in cost of reproduction and resource allocation studies for a variety of reasons: they are bet-hedgers utilizing both asexual and sexual reproduction strategies, multiple clonal individuals in close proximity can increase confidence that variation is due to environmental effects on a population, and nutrient sources are direct as mosses lack storage structures so reliance on stored resources can not skew mechanistic patterns as may be the case in seed plant studies (Stark 2005). Cost of reproduction has been shown in certain species of mosses. In Dicranum polysetum sporophyte production negatively impacted apical gametophyte growth as measured by biomass the following year (Ehrlén, Bisang, and Hedenäs 2000). In Pterygoneurum ovatum clonal growth, as measured by ability to produce protonema and shoots, was reduced in apical meristems that had supported sporophytes (Stark, Brinda, and McLetchie 2009). In Hylocomium splendens sporophyte production negatively impacted growing gametophyte segments (Rydgren and Okland 2003). If sexual reproduction incurs a cost in the current or subsequent season this may be a response to environmental extremes.

Stress can be defined as any biotic or abiotic influence that causes a plant to reduce biomass of any particular structure or in total biomass (Grime 1981). Stress, as measured in colder average temperature and shorter growing season associated with increasing altitude, was negatively correlated with male sex expression (gametangia) in Hypnum cupressiforme in the tropics of Africa (Bisang and Hedenäs 2005). In Mnium undulatum and M. hornum vegetative reproduction was severely impacted by stress in the 
form of prolonged desiccation, with $100 \%$ mortality of male gametophytes versus $77 \%$ survival in females (Mishler and Newton 1988). In Syntrichia caninervis of the Mojave Desert sex expression generally, male sex expression in particular, and sporophyte presence was impacted negatively by stress as defined as prolonged exposure, with associated high desiccating wind and UV irradiation, and low soil moisture (Bowker et al. 2000). In another desert system, Tortula ruralis male gametangia were not observed in the Organ Mountains of Arizona, possibly due to desiccation and environmental heterogeneity (Mishler and Oliver 1991). Male sexual structures, which have been shown to incur a high energetic cost and take more time to develop in $>80 \%$ of dioicous moss? species studied ( $\mathrm{n}=96)$, can fail to fully develop under resource limitation and thus limit fertilization potential (Stark, Mishler, and McLetchie 2000). In Grimmia orbicularis sporophytes shed during elongation phase because of irregular desiccation and hydration patterns (Stark 2005). In five moss species the number of sporophytes per shoot increased as distance from geothermal soils increased and temperatures decreased in Lassen Volcanic National Park, California (Eppley et al. 2011). These patterns support the hypothesis that in dioicous, perennial mosses trade-offs between survival and sexual reproduction may exist during periods of environmental extremes (Glime and Bisang 2014b). An important gap in our understanding remains: post-syngamy, do mosses in extreme environments differentially allocate resources to sporophytes as measured by gametophyte to sporophyte morphological ratios, spore number, and/or allocation to spores as measured by successful germination and establishment.

I characterized the response of moss reproductive characteristics to simulated anthropogenic nitrogen deposition in a manipulative experiment conducted across an 
environmental disturbance gradient in the Mount St. Helens (MSH) National Volcanic Monument. The disturbance gradient includes typical primary succession landscapes closest to the center of the blast, where no biological legacies survived and all species must migrate from the periphery to colonize a harsh landscape. These sites are compared to sites in the blowdown zone, further from the crater, where the forest was destroyed but soils, root structures, and propagules survived. Populations at these two points on the disturbance gradient can be compared in order to test how stress affects species attempting to colonize the primary succession zone. By comparing morphological features of three dominant species I sought to determine if sexual or asexual reproductive effort is increased under varying environmental stress. I measured three variables:

1) The occurrence of successful fertilization can be measured by presence of sporophytes. I predicted that if drought or nutrient stress? limiting successful mating then the presence of sporophytes in any stage will be a measure of those successful events. Successful mating events do not equate with plant success over all, however, as sporophyte initiation can be aborted once initiated, and resource allocation to spores can be limited (Mogensen 1981).

2) Allocation to sporophyte growth over gametophyte growth can be measured by length and weight of constituent parts. I predicted that a tradeoff prioritizing gametophyte growth over sporophyte growth would indicate a post fertilization control over investment in sexual reproduction. If environmental conditions worsen after gametangia formation and gamete dispersal, female mosses may be able to conserve resources by disinvesting in allocation to sporophytes. Whether this is a passive or active mechanism depends on how individually the sporophyte can control its metabolism. We know that 
moss sporophytes can control water and $\mathrm{CO}_{2}$ balance through simplified stomata and that they photosynthesize (Ligrone, Duckett, and Renzaglia 2012), but it has also been shown that sporophytes are dependent on the gametophyte for water and nutrient supply, as well as protection from desiccation in the form of the haploid calyptra (Budke, Goffinet, and Jones 2013).

3) Allocation to spores is also a measure of allocation to sexual over asexual reproduction. This factor can be measured by spore counts of individual capsules as well as scoring overall germination success. I predicted that if there is a further control mechanism prioritizing gametophyte (asexual) reproduction and/or survival over sexual reproduction as measured by sporophyte survival, then spore production, survival and germination success can also be used an indicator of? such a mechanism. While germination in laboratory may not necessarily equate with successful germination in the field (Kulke 2000) it can be used as an indicator of a process whereby if environmental conditions become unfavorable after fertilization and sporophyte capsule maturation, allocation to further spore development can be halted. If such mechanisms can be shown then it follows that mosses have similar developmental control mechanisms as those of seed plants that have evolved to ensure survival and success of offspring. 


\section{METHODS}

Sites and treatments - On May 18, 1980, Mount St. Helens (MSH), a 2,950 m stratovolcano located in the Gifford Pinchot National Forest in southwest Washington, USA trembled under an 5.1 magnitude earthquake epicentered $2 \mathrm{~km}$ below. In a matter of seconds, a landslide-debris avalanche on the north flank, the largest ever recorded, unleashing the tremendous pressure that had been accumulating since March of that year (Tilling, Topinka, and Swanson 2002). An unprecedented and unpredicted lateral pyroclastic surge of up to $1,000 \mathrm{kph}$ blew down the forest in a $350 \mathrm{~km}^{2}$ fan, up to $30 \mathrm{~km}$ away from the center of the explosion. Subsequent pyroclastic flows covered the areas near the cone in up to $40 \mathrm{~m}$ of $850^{\circ} \mathrm{C}$ rock (Major 1984, del Moral 1983). Melted glaciers and snow mixed with boulders and debris sending cataclysmic mudslides in every direction, channeled through existing river valleys, knocking out bridges and inundating the Columbia and Cowlitz rivers $86 \mathrm{~km}$ away. Ash and tephra fall affected thousands of $\mathrm{km}^{2}$ (Endo et al. 1981). What was created in an instant was essentially a $20 \mathrm{~km}^{2}$ desert devoid of all life bordered by $370 \mathrm{~km}^{2}$ of leveled Douglas fir (Pseudotsuga menziesii) dominated forest with $300^{\circ} \mathrm{C}$ debris deposition reaching $1 \mathrm{~m}$ thick and a further $27 \mathrm{~km}^{2}$ scorch zone where the bleached trunks of giant trees still stand lifeless. Scientists have been studying how the landscape is recovering for the past three decades (Lippman and Mullineaux 1981, Swanson and Major 2005).

In order to test the effects of anthropogenic nitrogen deposition on plant communities on MSH, sixty, 8-x-8 m plots were set up in four sites in 2013, with and without nitrogen treatments. These plots were initially set up by and are being used in collaboration with J. Bishop and M. Miller-Pierce, Washington State University, 
Vancouver as a part of a larger experiment examining the interacting effects of anthropogenic $\mathrm{N}$ and invasive willow wood boring beetles on succession. These plots allowed me to examine the effects of nitrogen on moss morphology as well as provided an environmental gradient from the center of the primary successional zone, known as the Pumice Plain, to the secondary succession zone $11 \mathrm{~km}$ away. Two sites, termed East and West, are located on the Pumice Plain and two sites, termed Harmony and Norway, are located in the blowdown zone. Their approximate coordinates and elevations are: East sites, 46.240587, -122.170939, 1,179 m elevation, West sites, 46.240682, -122.182278, 1,150 m elevation, Harmony Falls Trailhead, 46.274946, -122.101809, 1,280 m elevation, Norway Pass Trailhead lower, 46.303767, -122.083941, 1,130 m elevation. Plots differed among treatment plans in two ways: those with or without $\mathrm{N}$-addition broadcast in the form of salt crystals of sodium nitrate $\left(\mathrm{NaNO}_{3}\right)$ and ammonium nitrate $\left(\mathrm{NO}_{3} \mathrm{NH}_{4}\right)$ at rates of 0,8 or $16 \mathrm{~kg} / \mathrm{hectare} /$ year, and those with or without a pesticide treatment that was used to exclude Salix specialist beetles. The treatments were fully factorial except that the $8 \mathrm{~kg} / \mathrm{ha}$ treatment was omitted at the Harmony and Norway secondary succession sites, yielding 18 plots in 3 blocks at each fo the primary sites and 12 plots in 3 blocks at each of the secondary sites. I do not further consider the effect of pesticide treatments because pesticide was sprayed only on the base of willows and all samples for this study were collected at least $1 \mathrm{~m}$ from a willow.

Descriptions and sampling - In order to assess potential dispersal and establishment differences across sites, presence/absence of sporophytes for each species was collected for each plot. Individual plants were sampled from each site using a random selection procedure. Using a rough grid in each $8 \mathrm{~m} \mathrm{X} 8 \mathrm{~m}$ plot, one to two individuals with 
undehisced, mature sporophytes was randomly collected in each square meter. Where no individual of the target life stage was encountered in any give square meter, sampling continued in the plot until up to 10 individuals of each species was collected for morphological assessment and germination studies. All samples were collected over two days in June, 2015

Study Taxa - Polytrichum juniperinum Hedw. (Polytrichaceae), common name juniper haircap moss, is a dioicous, acrocarpous moss with worldwide distribution and a wide environmental tolerance. It has been observed occurring in recently disturbed boreal and subboreal spruce forests, shrublands, peatlands, coniferous forests, grasslands, alpine communities and herbaceous subalpine communities (Fryer 2008). In the Pacific northwest, $P$. juniperinum occurs in subalpine fir-Engelmann spruce forests and Douglas fir-mountain grassland transition zones (Lang 1961). It is a dominant moss with $R$. canescens, forming 23\% cover on Wier Prairie in southwest Washington (Tveten; Fonda 1999). A large moss, gametophyte stems range from $1-10 \mathrm{~cm}$ tall, and consist of multiple whorls of lanceolate leaves, $4-8 \mathrm{~mm}$ long. Leaves open when moist, and contract close to the stem when dry. Margins are recurved with leaf surfaces containing central groove with multiple rows of lamellae. These features allow for greater moisture retention and photosynthesis in xeric habitats (Smith 1971). Racomitrium (Niphotrichum) canescens (Hedw.) Brid. (Grimmicaceae) is an acrocarpous moss, know as roadside moss or hoary fringe-moss, and is ubiquitous in disturbed sites. Plants are yellowish to light green, and often occur in large tufts in a variety of substrates, but particularly gravelly or sandy soils. This species is found at $0-$ $4200 \mathrm{~m}$. elevation, across the North American continent and similar latitudes globally. 
Leaves are lanceolate, with serrate or entire hyaline (translucent) awns and a single costa (Vitt 1988). Gametophyte stems range from $3-10 \mathrm{~mm}$ long by $0.8-1.3 \mathrm{~mm}$ wide. Seta range from 5-25 $\mathrm{mm}$ long and are dark red to brown, and hold brown cylindrical capsules that range from 1.5-2.5 mm, holding spores of 8-11 um. (Hastings 1997)

Ceratodon purpureus (Hedw.) Brid. (Dicranaceae) is a dioicous, acrocarpous moss with worldwide distribution and it is one of the first mosses to occupy disturbed sites and is quite prevalent in urban environments (Jules and Shaw 1994). C purpureus can be found in pure stands or interspersed within mixed moss stands and prefers mineral soils and direct sun, though it can grow on a variety of substrates and tolerates shading. $C$. purpureus is easily identified when sporophytes are present by the shiny red setae and, when dry, by the copper-toned capsules. Setae have the unique feature of being twisted, and with hydration and rehydration they twist and untwist, which may aid in dispersal (Vitt 1988). Gametophytes are low-growing compared to sporophytes and range in color from deep green to reddish brown.

Morphological measurements - In order to compare possible environmental and resource effects on morphology, moss individuals were dried to constant mass at $50^{\circ} \mathrm{C}$ and measurements of seta and gametophyte length were obtained to the nearest $\mathrm{m}$ using digital calipers. Mass was measured using a Mettler Toledo microbalance to the nearest $\mu \mathrm{g}$ for gametophyte, seta, capsule and calyptra. Seta specific density (mg/mm) and gametophyte specific density $(\mathrm{mg} / \mathrm{mm})$ were calculated when possible, as was gametophyte to sporophyte ratio.

Spore counts - In order to test for differences in allocation to spore production among sites and nitrogen addition treatment, total spores per capsule were estimated from 40 
individuals of each species, ten from each site, using hemocytometers (Incyto, C-Chip DHC-N01, Neubauer Improved). Life stage was mature, calyptra intact in the case of $P$. juniperinum, and operculum cap intact in both cases. Each capsule was surface sterilized by immersing in $2 \mathrm{~mL}$ of $10 \%$ clorox solution and agitating gently for one minute and rinsing twice in sterile tap water for 2 minutes. Using fine forceps capsules were opened in $1 \mathrm{~mL}$ of sterile tap water, thoroughly agitated using a vortexer, and $20 \mu \mathrm{L}$ of this $100 \%$ spore solution were then pipetted into cytometers and spores counted on a micro-grid. Average spore number was then estimated for number of spores per capsule by multiplying the volume of the hemocytometers to reach the average volume of the capsule.

Germination rate - In order to account for environmental effects on spore germination rate, 16 individuals from each species were randomly selected for germination studies, two individuals from nitrogen addition plots and two from control plots from each of the four sites. Spore slurry from each capsule was diluted to a concentration of $12.5 \%$ of original concentration. Five replicates for each capsule were plated on petri dishes with sterile agar. Dishes were kept in a grow room with a $12 \mathrm{~h}$ light/dark cycle and ambient temperature of $25^{\circ} \mathrm{C}$. Germination was estimated every 2 days by counting germinated spores along a random transect across the agar plate using a confocal light microscope at 100X magnification. Germination was defined as elongation and cell division of the original spore into the first phase of tissue formation.

Statistical analysis -We used analysis of variance to determine the effects of treatment (nitrogen addition and control), site (West, East, Harmony, and Norway), nested in succession (primary and secondary succession), and the interaction between these factors 
on the response variables of morphology (gametophyte length, gametophyte mass, gametophyte specific density, seta length, seta mass, seta specific density, capsule mass, calyptra mass, total sporophyte mass, spore count and maximum germination). Data was analyzed using a statistically conservative approach to correct for multiple simultaneous statistical tests on the same data set, decreasing the likelihood of reporting false positives. Using the Bonferroni correction the critical alpha level of 0.05 was lowered to 0.017 . Chi squared tests were used for presence/absence of sporophytes by plot. To analyze the effects of these factors on percent of total spore count germinated over time, germination data were analyzed using a repeated measures MANOVA. Proportion data were arcsine transformed before analysis to correct for a non-binomial distribution. Tukey's post hoc analyses were used to determine significant differences among factors. All analyses were performed using JMP Pro (version 12.0.1, 2015 SAS Institute Inc.). 


\section{RESULTS}

\section{Polytrichum juniperinum morphological responses}

Gametophyte length - Mean gametophyte length was significantly different among sites $(P<0.01$; Table 1), with gametophytes from the Norway site $(\bar{x}=20.14 \mathrm{~mm})$ significantly greater than gametophytes from the West $(\bar{x}=14.64 \mathrm{~mm})$ and Harmony $(\bar{x}=13.12 \mathrm{~mm})$ sites, and gametophytes from the Harmony site significantly shorter than those from the Norway and East sites $(\bar{x}=18.62 \mathrm{~mm}$; Figure 1A). Data from control plots in the East site were not collected and comparisons were not included in analysis of treatment effect. Mean gametophyte lengths in nitrogen additions plots in East $(\bar{x}=$ $15.04 \mathrm{~mm})$ and Harmony $(\bar{x}=9.68 \mathrm{~mm})$ sites were significantly reduced compared to those in both treatment $(\bar{x}=29.24 \mathrm{~mm})$ and control $(\bar{x}=19.03 \mathrm{~mm})$ plots in the Norway site $(P<0.05$; Figure 1B). No significant difference between mean gametophyte lengths was detected between nitrogen addition or control plots. Though initial statistical analysis indicated a significant interaction between site and nitrogen addition on gametophyte length, Bonferroni correction revealed a higher significance threshold was needed for multiple comparisons and Type 1 errors were corrected (Table 1).

Gametophyte mass - Mean gametophyte mass was significantly different by site $(P<$ 0.01; Table 1). Gametophyte mass from the West site was significantly lower than the Norway site $(\bar{x}=2.02 \mathrm{mg}$ and $\bar{x}=3.01 \mathrm{mg}$, respectively), and gametophyte mass from the Harmony site was significantly lower than East site $(\bar{x}=1.91 \mathrm{mg}$ and, $\bar{x}=2.89 \mathrm{mg}$, respectively; Figure 2A). Significant differences in mean mass were not detected based on nitrogen addition treatment nor between site and nitrogen treatment (Figure 2B). 
Gametophyte specific density - Whole model significance was detected, though individual factors were not significant alone $(P<0.05$; Figure 3A). Significant differences between mean gametophyte specific density (GSD) were detected between two sites. Tukey's HSD showed that within the primary succession zone, GSD from the nitrogen addition plots of the East site were significantly greater than GSD from the nitrogen addition plots from the West site $(\bar{x}=0.736 \mathrm{mg} / \mathrm{mm}$ and $\bar{x}=0.397 \mathrm{mg} / \mathrm{mm}$, respectively). No significant differences in GSD were detected with nitrogen addition or in the interaction between the two variables (Figure 3B).

Calyptra mass - Calyptra mass was significant by site $(P<0.01$; Table 1). Overall, calyptrae in the Harmony site were significantly lower than those in the Norway site $(\bar{x}=0.90 \mathrm{mg}$ and $\bar{x}=1.23 \mathrm{mg}$, respectively; Figure 4A). Nitrogen addition in the West site reduced calyptrae mass compared to those in the treatment plots of the Norway site ( $\bar{x}=0.90 \mathrm{mg}$ and $\bar{x}=1.28 \mathrm{mg}$, respectively). Treatment in the East site increased calyptrae significantly compared to calyptrae in the Harmony site $(\bar{x}=1.30 \mathrm{mg}$ and $\bar{x}=$ $0.92 \mathrm{mg}$, respectively). Harmony control plots $(\bar{x}=0.88 \mathrm{mg})$ showed significantly lower calyptrae mass than those in the East treatment plots and both Norway control $(\bar{x}=1.19$ $\mathrm{mg}$ ) and treatment plots (Figure 4B).

Sporophyte presence - Results indicated significant decreases in sporophyte presence in plots of the West, East and Harmony sites (chi square, $\chi^{2}=6.67, P<0.01 ; \chi^{2}=5.4, P<$ $0.05, \chi^{2}=8.07, P<0.01$, respectively). Fewer than $40 \%$ of plots contained detectable sporophytes in these three sites. In the Norway site two thirds of plots contained sporophytes which was not significantly different than the expected observation. 
Seta length - Significant difference in seta length was detected among sites $(P<0.0001$; Table 1). Norway site setae were significantly greater $(\bar{x}=48.40 \mathrm{~mm})$ than West $(\bar{x}=$ $39.69 \mathrm{~mm})$ and Harmony $(\bar{x}=32.85 \mathrm{~mm})$ site setae. East site setae $(\bar{x}=41.56 \mathrm{~mm})$ were also significantly greater than Harmony site setae (Figure 5A). Within sites, no significant difference between mean seta length was detected between $\mathrm{N}$-addition or control plots. Significant interactions were detected $(P<0.05)$. Setae in the Norway site nitrogen addition plots $(\bar{x}=50.50 \mathrm{~mm})$ were significantly higher than setae in the East nitrogen addition plots $(\bar{x}=42.37 \mathrm{~mm})$, Harmony treatment $(\bar{x}=27.39 \mathrm{~mm})$ and control $(\bar{x}=38.30 \mathrm{~mm})$ plots, and West treatment plots $(\bar{x}=35.53 \mathrm{~mm})$. Setae in the Harmony site treatment plots were also significantly lower than those in the Norway control plots $(\bar{x}=46.31 \mathrm{~mm})$, as well as the East treatment plots, West control plots $(\bar{x}=43.85)$, and West treatment plots (Figure 5B).

Seta mass - Significant difference between mean seta mass was detected by site $(P<$ 0.001; Table 1). Setae in the Norway site $(\bar{x}=2.65 \mathrm{mg})$ were significantly higher than West $(\bar{x}=1.96 \mathrm{mg})$ and Harmony $(\bar{x}=1.71 \mathrm{mg})$ sites, and mean setae mass in the Harmony site was significantly less than that in the East site $(\bar{x}=2.40 \mathrm{mg}$; Figure 6A). No significant differences between sites based on treatment were detected. In the Norway site treatment plots $(\bar{x}=2.89 \mathrm{mg})$ setae mass was significantly greater than in the Harmony site treatment plots $(\bar{x}=1.55 \mathrm{mg})$ and control plots $(\bar{x}=1.87 \mathrm{mg})$, as well as compared to West site treatment plots $(\bar{x}=1.85 \mathrm{mg})$. Setae mass in the Harmony site treatment plots was also significantly less than setae mass in the East treatment plots $(\bar{x}=$ 2.59 mg; Figure 6B). 
Seta specific density (SSD) - Significant differences in seta specific density were detected $(P<0.001 ;$ Table 1$)$. No significant difference by site was detected nor any based on an interaction effect of the two variables (Figure 7A). Significant differences within sites were detected based on nitrogen addition with SSD from nitrogen addition plots greater than SSD from control plots $(\bar{x}=0.056 \mathrm{mg} / \mathrm{mm}$ and $\bar{x}=0.049 \mathrm{mg} / \mathrm{mm}$, respectively). Analysis of difference by plot and treatment show SSD in the East site nitrogen addition plots $(\bar{x}=0.061 \mathrm{mg} / \mathrm{mm})$ was significantly greater than SSD in Norway control plots $(\bar{x}=0.052 \mathrm{mg} / \mathrm{mm})$, West site control plots $(\bar{x}=0.047 \mathrm{mg} / \mathrm{mm})$ and Harmony site control plots $(\bar{x}=0.047 \mathrm{mg} / \mathrm{mm})$. Norway site nitrogen addition plot $\operatorname{SSD}(\bar{x}=0.057 \mathrm{mg} / \mathrm{mm})$ was also significantly greater than Harmony site control plots (Figure 7B).

Capsule mass - Mean capsule mass was significant by site $(P<0.001$; Table 1$)$, with capsules from the Norway site $(\bar{x}=3.01 \mathrm{mg})$ significantly greater than capsules from the West $(\bar{x}=2.02 \mathrm{mg})$ and Harmony $(\bar{x}=1.91 \mathrm{mg})$ sites, and capsules from the Harmony site also significantly less than those from the East site $(\bar{x}=2.89 \mathrm{mg}$; Figure $8 \mathrm{a})$. No significant difference between mean capsule mass was detected between within-site nitrogen addition or control plots, nor was there a detectable significant interaction effect of site and treatment. Control $(\bar{x}=2.93 \mathrm{mg})$ and nitrogen addition plots $(\bar{x}=3.08 \mathrm{mg})$ in Norway and nitrogen addition plots in the East site $(\bar{x}=2.95 \mathrm{mg})$ yielded significantly greater capsule mass than those from nitrogen addition plots in the West $(\bar{x}=1.75 \mathrm{mg})$ and Harmony $(\bar{x}=1.62 \mathrm{mg})$ sites (Figure $8 \mathrm{~B})$.

Total sporophyte mass - Mean total sporophyte mass was significant by site $(\mathrm{p}<0.001$; Table 1), with sporophytes from the Norway site $(\bar{x}=5.66 \mathrm{mg})$ significantly greater than 
sporophytes from the West $(\bar{x}=3.98 \mathrm{mg})$ and Harmony $(\bar{x}=3.62 \mathrm{mg})$ sites, and sporophytes from the Harmony site also significantly less than those from the East site $(\bar{x}=5.30 \mathrm{mg}$; Figure 9A). No significant difference between mean capsule mass was detected between within-site nitrogen addition or control plots, nor was there a detectable significant interaction effect of site and treatment. Sporophyte mass from nitrogen addition plots in the Norway site $(\bar{x}=5.97 \mathrm{mg})$ were significantly greater than Harmony $\operatorname{control}(\bar{x}=4.07 \mathrm{mg})$ and treatment $(\bar{x}=3.17 \mathrm{mg})$ plots as well as West treatment plots $(\bar{x}=3.59 \mathrm{mg})$. Harmony treatment plots were also significantly greater than East treatment plots $(\bar{x}=5.55 \mathrm{mg}$; Figure 9B).

Spore count - Differences in mean number of spores per capsule can be seen by site though spore count was not statistically significant in the full model by site, nitrogen addition, nor by interaction effect (Table 1$)$. Harmony site had the highest count $(\bar{x}=$ 919,337.73), followed by the East site $(\bar{x}=706,565.21)$, then the West site, $(\bar{x}=$ 590,444.26) with the Norway site having the lowest count $(\bar{x}=377,671.74$; Figure 10B $)$. Maximum germination - Maximum germination was significant by site $(P<0.05$; Table 1), with spores from Norway germinating at a high of $\bar{x}=17.7 \%$ of the total count, significantly greater than maximum germination in the East site $(\bar{x}=2.9 \%)$ and Harmony site $(\bar{x}=<0.5 \%)$. Maximum germination in the Harmony site was also significantly lower than maximum germination in the West site $(\bar{x}=14.3 \%$; Figure $10 \mathrm{~B})$. Germination rate - Polytrichum juniperinum mean germination rate was significantly different by time $(P<0.01)$, and site $(P<0.05$; Table 2$)$. Interaction between site and nitrogen addition was also significant $(P<0.01)$. Specifically at 15 days, germination rate from spores collected at the Norway site $(\bar{x}=17.7 \%)$ was significantly higher than 
germination rate in the East $(\bar{x}=3 \%)$ and Harmony sites $(\bar{x}=<0.5 \%)$, and Harmony site germination was significantly less than West site germination rate $(\bar{x}=14 \%$; Figure 13a).

\section{Ceratodon purpureus morphological responses}

Sporophyte presence - Sporophyte presence was significantly lower than expected in plots of the West, East and Harmony sites (chi square, $\chi^{2}=9.6, P<0.01 ; \chi^{2}=11.267, P$ $<0.001, \chi^{2}=4.267, P<0.05$, respectively). Fewer than $40 \%$ of plots contained detectable sporophytes in these three sites. In the Norway site two thirds of plots contained sporophytes which was not significantly different than the expected observation Total sporophyte mass - No significant differences between mean total sporophyte mass were detected in C. purpureus samples (Table 1). Sporophytes from the East site were on average higher $(\bar{x}=0.41 \mathrm{mg})$ than those in the Harmony site $(\bar{x}=0.31 \mathrm{mg})$, and the Norway site $(\bar{x}=0.30 \mathrm{mg})$, with sporophytes from the West site $(\bar{x}=0.20 \mathrm{mg})$ having the lowest mean mass (Figure 11).

Spore count - Differences in mean number of spores per capsule can be seen by site though spore count was not statistically significant in the full model by the factors site, nitrogen addition, nor by interaction effect. Sporophytes from the Harmony site had the highest spore count $(\bar{x}=214,863.57)$, followed by the East site $(\bar{x}=164,536.39)$, then the West site, $(\bar{x}=109,866.70)$ with the Norway site having the lowest count $(\bar{x}=$ 59,539.53; Figure 12B). 
Maximum germination - Maximum germination did not differ among sites (Table 1). Spores from nitrogen addition plots germinated at a high of $\bar{x}=2.8 \%$ of the total count, greater than maximum germination in control treatment plots $(\bar{x}=0.4 \%$; Figure 12A). Germination rate - Germination rate of C. purpureus was not significant by site (Figure 13B) but was significant by nitrogen addition $(P<0.05$; Table 2$)$. On all days more spores from nitrogen addition plots germinated compared to spores from control plots (Figure 14). Interaction of time $(P<0.001)$, time and site $(P<0.01)$ and time and $\mathrm{N}$ addition $(P<0.001)$ were also all significantly different (Table 2$)$. 


\section{DISCUSSION}

\section{Gametophyte and sporophyte comparison}

Plants within landscapes recovering from total biologic devastation are under greater environmental constraints as compared to those in landscapes undergoing secondary succession, namely, they are subject to a greater degree of potential stress caused by higher surface temperatures, and lower soil water and nutrient retention (Odum 1969; Coleman, Crossley, and Hendrix 2004; Wood and del Moral 1987). Stress tolerant plant species, and populations and individuals within those species, all vary in their responses to stress. Measurable negative responses may not be as pronounced in mosses that have evolved to survive in otherwise deadly conditions, particularly due to their adaptations to survive total desiccation and low nutrient availability. Central to the predictions of my study, however, is that differences in factors affecting plant success in the extreme abiotic conditions associated with primary succession are measurable and can provide further insight into those evolved characteristics that make survival in a changing environment possible. In the MSH system, mosses may be differentially allocating resources to sporophytes and spores. Trade offs as measured by sporophyte to total mass ratios may not be incurred in bet hedging species.

Showing whether mosses allocate nutrients differentially between asexual and sexual reproduction is difficult as mosses exhibit such extreme phenotypic plasticity, a strategy itself thought to compensate for genetic adaptation to environmental changes in a life-form with a stabilized genome due to dominant haploidy and asexual reproduction (Mishler 1988). Comparisons of moss gametophyte measurements across an 
environmental gradient are not in and of themselves a measure of success but they are a crucial first step in assessing stress-adaptive traits since gametophyte success is critical to successful sporophyte development and the consequential development, dispersal and germination of spores (Courtice, Ashton, and Cove 1978). In mosses, allocation to sexual reproduction has been shown to reduce gametophytic stem length (Zartman et al. 2015). Allocation differences to gametangia between sexes in dioicous mosses have also been shown (Bisang, Ehrlén, and Hedenäs 2006; Ehrlén, Bisang, and Hedenäs 2000; Bisang and Hedenäs 2005) and during nutrient deficiencies vascular plants allocate biomass to roots, the organs responsible for absorption of the deficient nutrient (Hermans et al. 2006). The corresponding organ in mosses would be the gametophyte as they lack roots and adsorb nutrients across their leaf surfaces. Any of these observations may indicate possible trade offs in mosses on MSH.

Here, I predicted that the dominant vegetative stage would be negatively correlated to abiotic stress as measured in reductions of gametophyte length and mass in primary succession sites and that once released from environmental constraints plants would show increased allocation to vegetative structures. My prediction was not fully supported. Significant differences in $P$. juniperinum gametophyte mass and length between sites were detected, though the observed patterns in gametophyte morphology are not explained when simply comparing primary succession sites to secondary succession sites. The results from comparing the gametophytes farthest from the leading successional edge (West), where environmental mitigation was predicted to be least, to the most mitigated secondary succession site (Norway), do follow the predicted pattern. However observations of gametophytes from the primary succession East site and the 
secondary succession Harmony site yielded contradictory results. These results may only support the theory that bryophytes exhibit phenotypic plasticity to a greater extent than vascular plants as a compensation for a lesser reliance on the genetic recombination that sexual reproduction provides (Mishler 1988).

If plants that evolved to survive long periods of stress, what Grime (1977) called stress-tolerators, possess plastic traits in order to maintain or halt metabolism than they would exhibit morphological differences in a predictable pattern along an environmental stress gradient. Moss gametophytes exhibiting lower length and mass may be initiating a successful stress avoiding strategy by reducing the overall size of their structures and surface area in order to reduce transpiration and thus conserve resources (Goldberg 1990). In the moss populations under study here, this strategy may be at work. Mosses in the Norway secondary sites may be released from having to conserve resources and reduce structures due to the more intact organic composition of the soils left after the eruption as well as the mitigating effects already established plants may be providing like the exponential increases of organic matter from plant litter with concomitant increases in soil nutrient and water retention, UV mitigation by shading, and diversification of soil biota. Plants may be responding to possible decreases in abiotic stress in the East site and increased abiotic stress in the Harmony site, due to fewer or more recent disturbance events respectively, or differences in resource patchiness that have yet to be measured. This may account for the patterns in gametophyte morphology observed from these two sites.

Additionally, though gametophyte specific density (GSD) was lower in the West site than in all other sites and nitrogen addition decreased GSD in the West site, no 
statistically significant differences between sites or treatments were detected in my model. The pattern is noteworthy because even though differences in mean gametophyte length and mass were detected by site, GSD measurements remained steady. To put it another way, even with perceived environmental differences, gametophytes remained constant in the amount of resources they allocated to growth as measured by GSD. Plants in more extreme environments may be remaining small, but the mean volumetric measurement of $0.60 \mathrm{mg} / \mathrm{mm}$ of growth across all sites indicates resource use efficiency and functionality may be preserved. This consistent growth rate may be evidence of a stress-tolerator strategy, indicative of a suite of physiological traits upon which natural selection is acting in P. juniperinum (Grime 1981). Reciprocal transplant studies in the future may provide incite into whether constant growth rate and carbon allocation in a genetically inherited trait in this species.

\section{Calyptrae, maternal investment}

A pattern of increased abiotic stress may explain reduced calyptra mass. In the Harmony site, lower calyptra mass was not mitigated by the addition of nitrogen and were significantly less than those measured from the Norway site. As a maternal investment into sporophyte resistance to dehydration the inability of the gametophyte to adequately develop a thick cuticle around the calyptra may explain the low sporophyte morphological measurements and low germination patterns seen in the Harmony site (Budke, Goffinet, and Jones 2013). Though gametophytic investment followed the pattern predicted, sporophyte and spore data indicate that allocation to viable spore development may have been limited as shown in the very low numbers of germinated spores, despite overall spore number, as well as significantly lower measurements in the 
Harmony site of seta length and mass, capsule and total sporophyte mass, and seta specific density.

\section{Sporophyte morphology}

Survival must be accompanied by a reproductive advantage as a condition of natural selection. If sexual reproduction is more advantageous under stress, than resource allocation to sporophytes and the developing spores - as measured by sporophyte morphology and germination success - is a more accurate predictor of moss fitness across the successional landscape. To address if stress is inducing asexual over sexual reproduction in early successional mosses, sporophyte development must be considered. The sporophyte in mosses, though photosynthetic, is dependent on the gametophyte for water and nutrient translocation (Buck and Goffinet 2000). One prediction in the MSH study system is that if mosses are initiating a more semelparous, annual plant strategy under more stressful conditions, than sporophyte development would be prioritized over gametophyte survival and that a cost of sex could be measured (Glime and Bisang 2014a). The alternative prediction is that a bet-hedging mechanism would be maintained under stress whereby allocation is equally distributed to vegetative and sexual reproduction (Stearns 1976). Under abiotic stress in the first scenario the expected result is a greater reduction in gametophyte growth as allocation to sporophyte success increased. In the second scenario, the prediction is that both gametophyte and sporophyte would be reduced in extreme abiotic stressed conditions.

I found that no significant differences existed between allocation to sporophytes as measured by the ratio of sporophyte mass to total mass. Significant differences among populations followed for both vegetative and sexual reproductive structures indicating 
equal partitioning of resources under environmental stress. In P. juniperinum, seta length was the only morphological measurement to be affected in site $\mathrm{x}$ nitrogen addition interaction. $\mathrm{N}$-addition reduced seta length in the more stressed Harmony and West sites and increased seta length in the Norway site. With greater stress, nitrogen may be diverted to more dense growth, as measured by the increased SSD associated with the treatment. Total sporophyte mass from $C$. purpureus followed similar patterns, where reduction in the most stressful site reduced mass. A greater number of morphological observations would allow a true intraspecies comparison of MSH mosses.

The prediction that nitrogen addition would significantly increase both gametophyte and sporophyte morphological characteristics was not observed. This is consistent with low-nutrient strategies of stress tolerant plants (Craine 2009). In order to avoid stress slow growth and the ability to only acquire what the individual can maintain allow for low nutrient loss and greater resource use efficiency (Grime 1977). A pattern in $\mathrm{N}$-addition plots of increased gametophyte length and mass as compared to control plots was observed in the presumptive least stressed site (Norway) whereas $\mathrm{N}$-addition reduced gametophyte length and mass in the presumptive most stressed site (West). If nitrogen addition increases allocation to sexual versus asexual reproduction in mosses and if that effect is greater when mosses are under abiotic pressure, than a pattern of increased capsule mass and decreased gametophyte investment would be observed with $\mathrm{N}$-addition and to a greater extent in the more stressed sites. In both the West site and the Harmony site, nitrogen addition decreased sporophyte mass as compared to controls, though not to statistically significant degree. 
The patterns I observed in the gametophyte morphology of $P$. juniperinum correspond to a similar pattern in sporophyte morphology. Seta length and mass was greatest in the Norway site with significant differences detected over West and Harmony site sporophytes. This finding is again contrary to the expected mitigation effects of secondary succession sites. The same pattern can be seen in mean capsule mass, and total spore mass. The expectation that sporophyte development in the East site would be significantly lower than secondary succession sites was also not observed. A negative correlation between gametophyte and sporophyte mass would have indicated a trade off, but no such correlation was observed. My observations that sporophyte mass and length mirror gametophyte measurements across sites does contribute supporting evidence to sporophyte dependence on gametophytes.

Seta specific density (SSD) was not significantly different by site either, though again, site differences in the other measurements of the sporophyte were detected. Of particular interest is that SSD was one of the only morphological measurements where nitrogen addition had a significant effect, in this case, increasing SSD. Stem specific density in tracheophytes has been measured as a functional trait indicative of a trade-off between growth rate and defense, with a high rate of growth and lower concentrations of defensive compounds correlating to a low SSD, and a slow growth rate and higher investment in defense correlating to higher SSD (Cornelissen et al. 2003; Kleyer et al. 2008). In the mosses under observation, I used setae as a proxy for stems as both are the gross morphology of diploid vertical growth and likely evolved to serve at least one similar function, to increase dispersal away from the parent thereby increasing the chances of genetic diversity in progeny. In all sites nitrogen increased seta density 
indicating that moss defense chemistry in the sporophyte may be $\mathrm{N}$-limited and with increased amounts of nitrogen mosses may be investing more in the defensive chemistry or the sporophyte and the concomitant protection of their spores. This also would indicate that with lower nitrogen seta can not grow as tall and dispersal area may be decreased. Since mosses are largely dependent on deposition of mosses on their surface, increases in atmospheric nitrogen may aid in this (Pearson 2000). With SSD, functionality and efficiency of resource allocation may also be conserved like that observed in GSD. Following Hedderson (2008), an analysis of reproductive effort as measured by the ratio of sporophyte mass to total mass revealed no significant differences by population or treatment. Still a further measurement of potential differences in allocation to sexual or asexual reproductive structures is measurement of spore development and success.

\section{Spore counts and germination}

Germination success is of particular interest when considering the roll of mosses on the primary succession of MSH. The earlier and more successful germinating individuals will have first access to resources, their head start exponentially advantageous over individuals occupying the same niche (Weinig 2000). If certain species of mosses are able to germinate to a greater degree and faster than their neighbors they will have first run of resources. In a landscape like MSH where soil development is greatly reduced early successional stage mosses may well be dominant for decades to come. In $P$. juniperinum no significant differences in mean spore number were detected, though capsules from the Harmony site were estimated to have the greatest number of spores and capsules form the Norway site were estimated to have the fewest. Estimated number of spores germinated was significantly different by site with capsules from the West site 
having the most germinated spores overall and capsules from the Harmony site having the fewest spores germinated. In the West site, though gametophyte and sporophyte measurements were significantly lower than in other sites, successful spore germination was the highest. Results from analysis of $C$. purpureus show that the Harmony site also had the highest total count of spores. Germination was not measured in the Harmony site however, so among the three sites analyzed the East site had the highest number of spores germinated.

Successful spore germination may be a more accurate test of moss fitness in disturbed landscapes. Are differences observed in spore count and germination rate between populations a result of genetic variation, environmental differences, or gene by environment interactions? In reciprocal transplant studies of life history traits in three species of Polytricaceae, Hedderson and Longton (2008) found influential genetic and environmental factors. Genetically determined negative correlations indicated trade offs between both spore number and diameter, as well as spores and vegetative propagation. These results are consistent with During's (2008) proposition that mosses in changing environments may be allocating resources differentially between number of spores versus size of spores, and between propagules resulting from sexual reproduction versus asexual reproduction.

Spores of C. purpureus showed a greater proportion of germination in nitrogen addition plots. This may be an indication that this species is able to allocate nutrients differentially in the critical phase of spore maturation. Overall however, a relatively small percentage of total spores initiated actually germinated. The germination study was terminated after two weeks and if it had continued may have revealed greater germination 
percentages. Nevertheless, since capsules are able to produce spores in the millions, even a percentage of $1 \%$ successful germination is enough to start thousands of new colonies away from the parental generation.

Mosses in the West site may be employing a strategy that conserves limited resources and uses them more efficiently, most notably by allocating more resources into a more limited number of spores ensuring their success. These data may support the hypothesis that a trade-off to sexual reproduction from asexual reproduction may be occurring under stress as measured by reduced gametophyte length and a great number of more successful germinated spores (Stearns 1989). Reproductive effort in the MSH populations as measured by sporophyte mass to total mass was not significantly different by site or treatment. Mosses may not be incurring a cost of reproduction in the way many tracheophytes have been observed to do (Meagher 1988). In cost of reproduction studies in mosses sporophyte development incurred a negative cost in terms of biomass of the gametophyte in some species (Ehrlén, Bisang, and Hedenäs 2000; Stark, Brinda, and McLetchie 2009; Rydgren and Okland 2003). Environmental factors may play a role in whether or not mosses initiate sexual reproduction in the first place, thus providing a strategy of avoidance of unnecessary resource allocation to resource taxing gametangia and sporophytes (Janice M Glime and Bisang 2014a). In totipotent taxa, where any cell may initiate reproduction, the consequences of skipped sexual reproduction have not been severe enough to warrant selection against the strategy. If sexual reproduction incurs a cost how might increased stress affect an individual plant's ability to survive and disperse? 


\section{CONCLUSION}

From my observations of mosses on MSH it would seem that there is a more dynamic response to differences in environment than predicted. Significantly lower gametophyte measurements from the Harmony site, and higher measurements from the East site indicate that locations in primary and secondary succession zones may be more nuanced in terms of resource patchiness and continued disturbance, especially on the moss scale. Other factors to consider when assessing environmental effects on MSH mosses would be slight changes in elevation, hydrological and erosion processes, air movement patterns, as well as proximity to trails and roads relative to human and animal disturbance. Growth of new photosynthetic and rhizomatic tissue prioritizes maintenance of existing individuals and prioritization of asexual, clonal propagation. In mosses we might expect to see greater investment in gametophytes under nutrient stress and a release from this condition with nutrient additions. These predictions were not observed though the most compelling evidence of at least equal investment into spore germination under stress if not greater investment as compared to less stressed sites indicate that mosses may well be able to prioritize investment in the next generation when abiotic stress increases. Future directions to support this hypothesis would involve reciprocal transplant studies to see if this is a phenotypically plastic response to environment, or if after thirty years, the mosses on the colonizing edge of MSH are being selected for dispersal. Improvements to this study would involve a greater number of observations on the physiological responses of mosses across all sites and a closer analysis of microenvironmental factors, particularly to determine if the West and Harmony sites are experiencing greater stress and/or disturbance. Next steps would be to deploy more 
environmental sensors to see if the initial environmental data patterns hold true for a greater number of sites and across multiple seasons. Initially interactions between the three dominant species were to be tested though this was not accomplished in particular due to the fact that $R$. canescens had already dispersed before collection could take place during the field season under study.

The modern facilitation model of primary succession predicts that early colonizers to disturbed sites will ensure the success of subsequent species by progressively mitigating abiotic extremes (Connell and Slatyer 1977) and classic resource competition theory explains how these subsequent species then take over (Shinozaki and Kira 1956). As is often the case in ecological studies, however, no explanation fits all systems and increasingly complex models must be developed to more fully account for the mechanisms and effects of any field observations (Firbank and Watkinson 1990). Incorporating the effects of bryophytes on primary successional plant communities is essential for the future design of accurate ecological models. 


\section{FIGURES}

A.

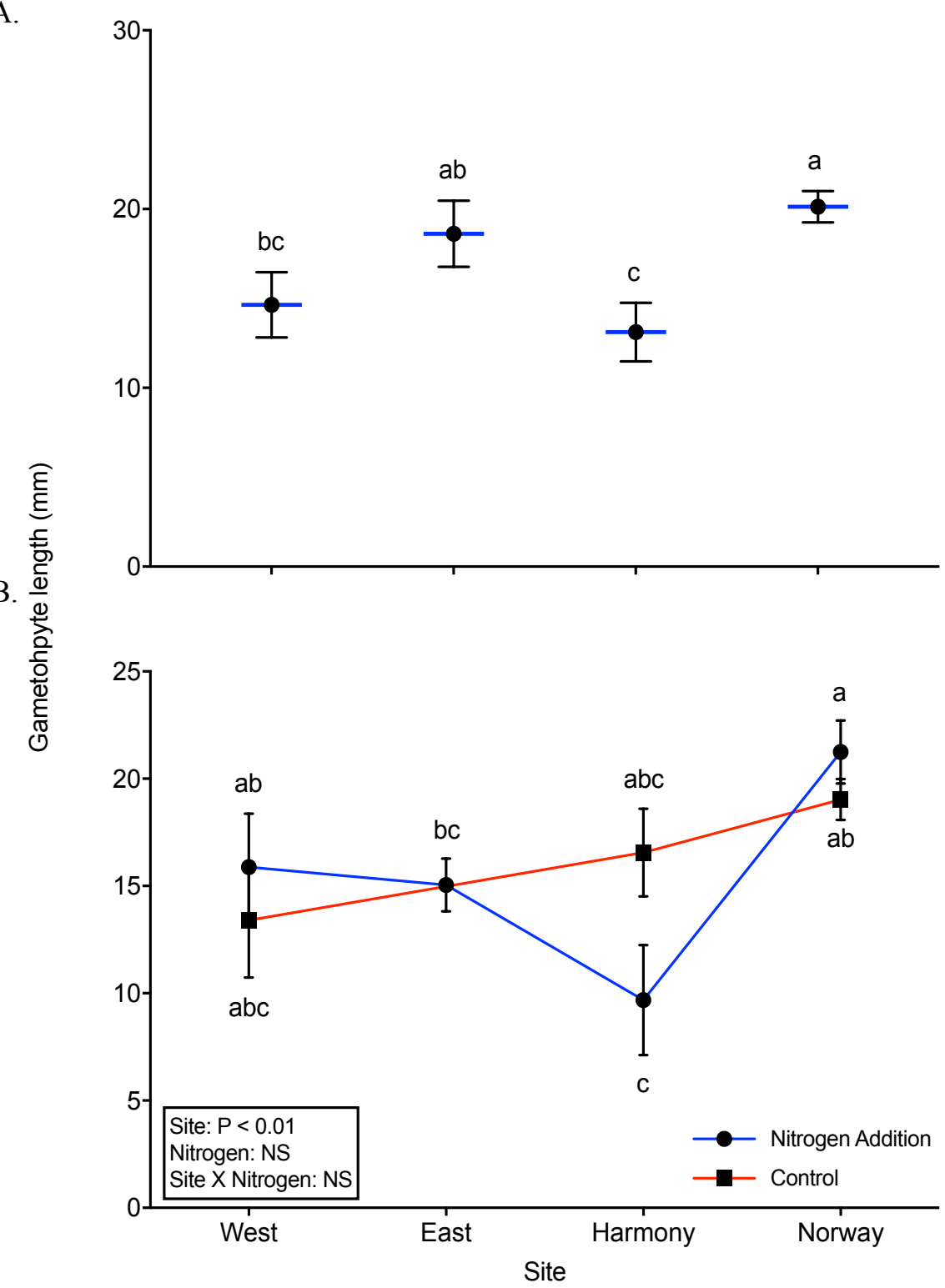

Figure 1: Least squared means ( \pm standard error) of gametophyte length $(\mathrm{mm})$ of $P$. juniperinum based on full model comparing site (primary succession sites West and East; secondary succession sites Harmony and Norway), treatment (nitrogen addition VS control) and interaction between the two variables $(\mathrm{DF}=5 ; \mathrm{F}=3.9982 ; \mathrm{P}=0.0021)$. A) Effect test results from site only $(\mathrm{DF}=2 ; \mathrm{F}=6.8981$;

$\mathrm{P}=0.0014)$ and $\mathrm{B})$ results from interaction $(\mathrm{DF}=2 ; \mathrm{F}=3.6634 ; \mathrm{P}=0.0283)$. Levels not connected by same letter are significantly different based on Tukey's HSD 
A.

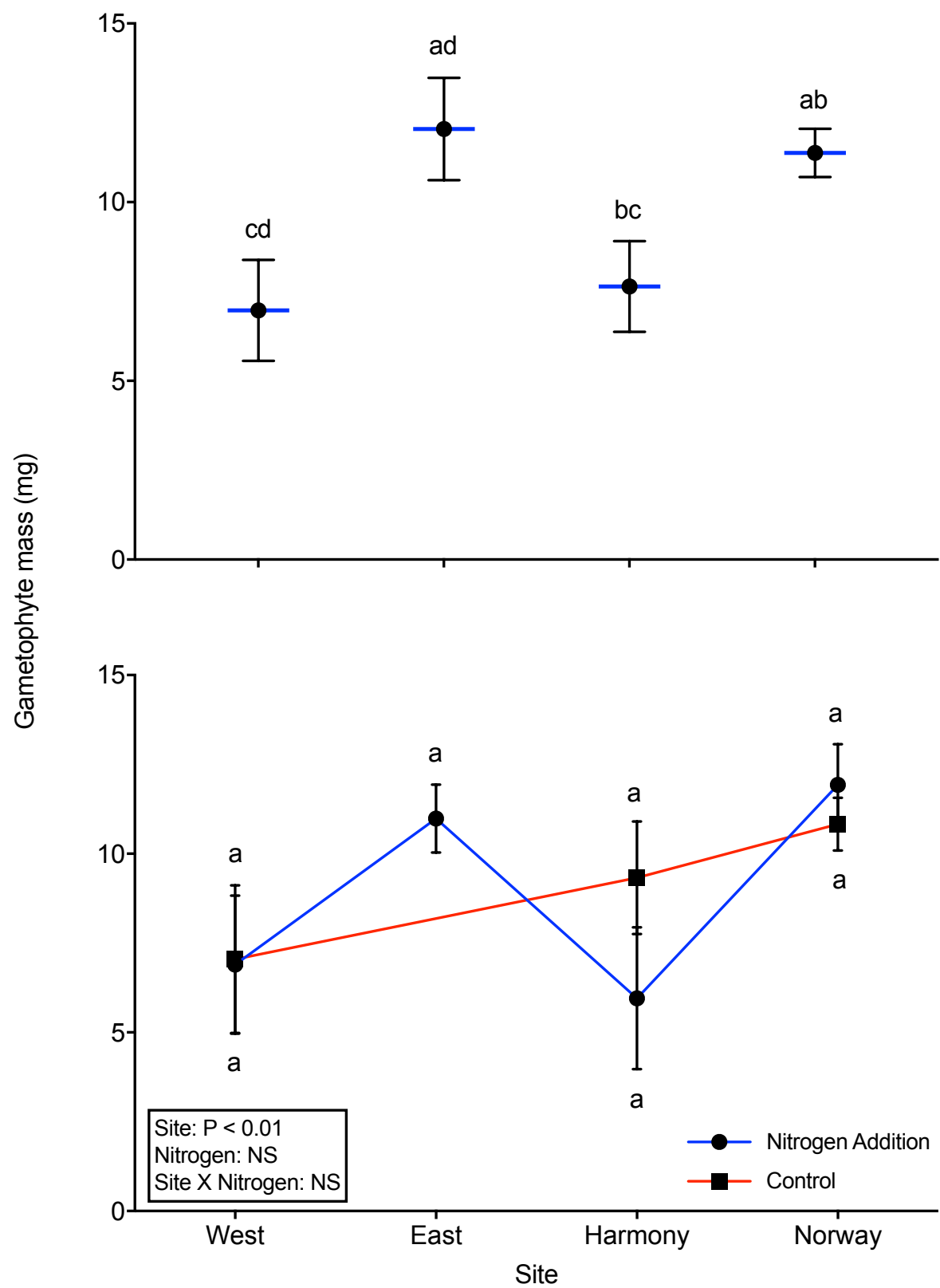

Figure 2: Least squared means ( \pm standard error) of gametophyte mass $(\mathrm{mg})$ of $P$. juniperinum based on full model comparing site (primary succession sites West and East; secondary succession sites Harmony and Norway), treatment (nitrogen addition VS control) and interaction between the two variables $(\mathrm{DF}=5 ; \mathrm{F}=2.0249 ; \mathrm{P}=0.0793)$. A) Effect test results from site only $(\mathrm{DF}=2 ; \mathrm{F}=4.9368$; $\mathrm{P}=0.0086)$ and $\mathrm{B})$ results from interaction $(\mathrm{DF}=2 ; \mathrm{F}=1.1145 ; \mathrm{P}=0.3312)$. Levels not connected by same letter are significantly different based on Tukey's HSD. 
A.

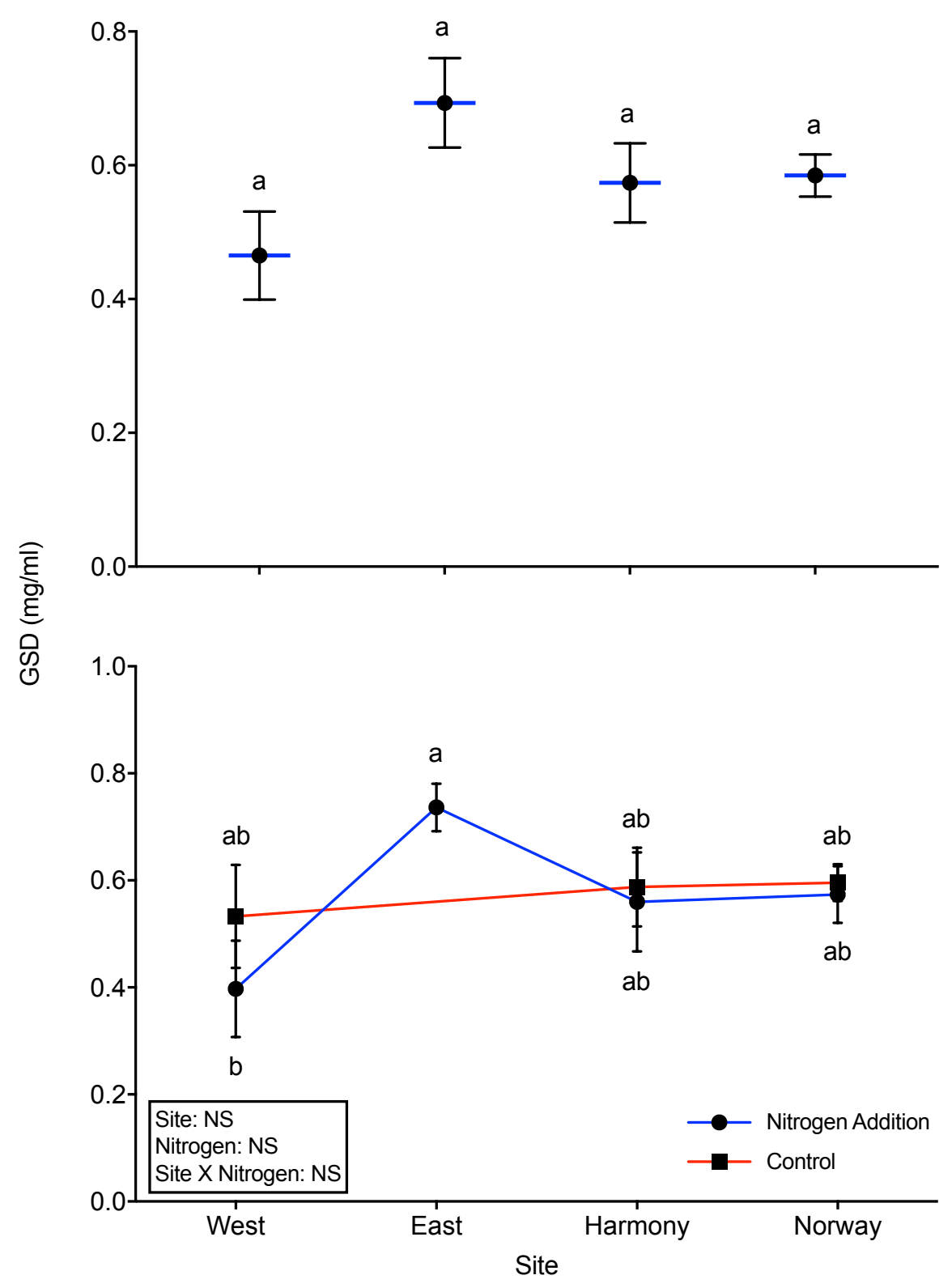

Figure 3: Least squared means ( \pm standard error) of gametophyte specific density (GSD; $\mathrm{mg} / \mathrm{mm}$ ) of $P$. juniperinum based on full model comparing site (primary succession sites West and East; secondary succession sites Harmony and Norway), treatment (nitrogen addition VS control) and interaction between the two variables ( $\mathrm{DF}=5 ; \mathrm{F}=2.5189 ; \mathrm{P}=0.0327)$. A) Effect test results from site only $(\mathrm{DF}=2 ; \mathrm{F}=1.8983 ; \mathrm{P}=0.154)$ and $\mathrm{B})$ results from interaction $(\mathrm{DF}=2 ; \mathrm{F}=0.4447 ; \mathrm{P}=0.642)$. Levels not connected by same letter are significantly different based on Tukey's HSD. 
A.

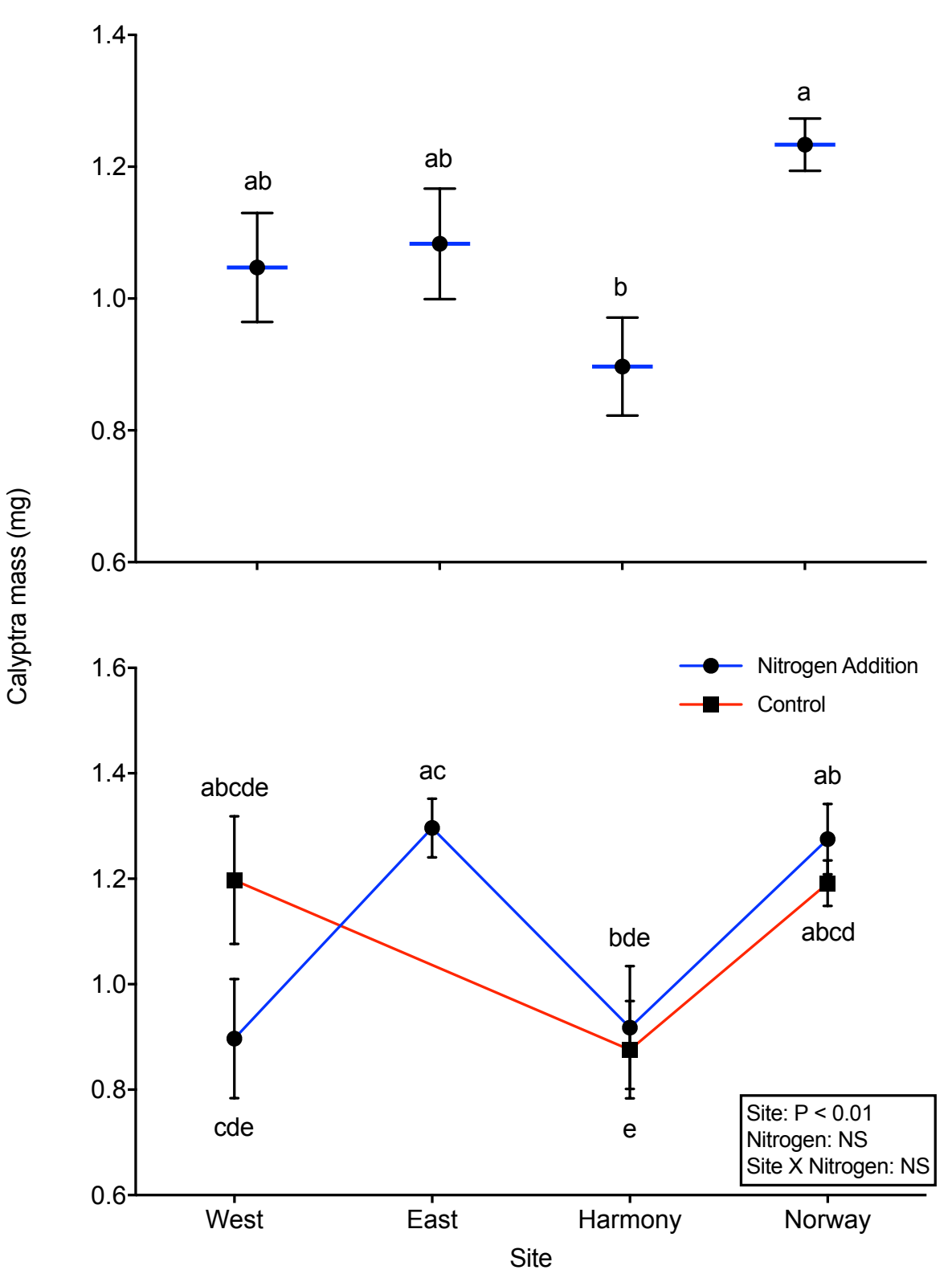

Figure 4: Least squared means ( \pm standard error) of calyptra mass $(\mathrm{mg})$ of $P$. juniperinum based on full model comparing site (primary succession sites West and East; secondary succession sites Harmony and Norway), treatment (nitrogen addition VS control) and interaction between the two variables $(\mathrm{DF}=5 ; \mathrm{F}=4.6982 ; \mathrm{P}=0.0006)$. A) Effect test results from site only ( $\mathrm{DF}=2 ; \mathrm{F}=6.9085$; $\mathrm{P}=0.0014)$ and $\mathrm{B}$ ) results from interaction $(\mathrm{DF}=2 ; \mathrm{F}=3.0552 ; \mathrm{P}=0.05050)$. Levels not connected by same letter are significantly different based on Tukey's HSD. 
A.

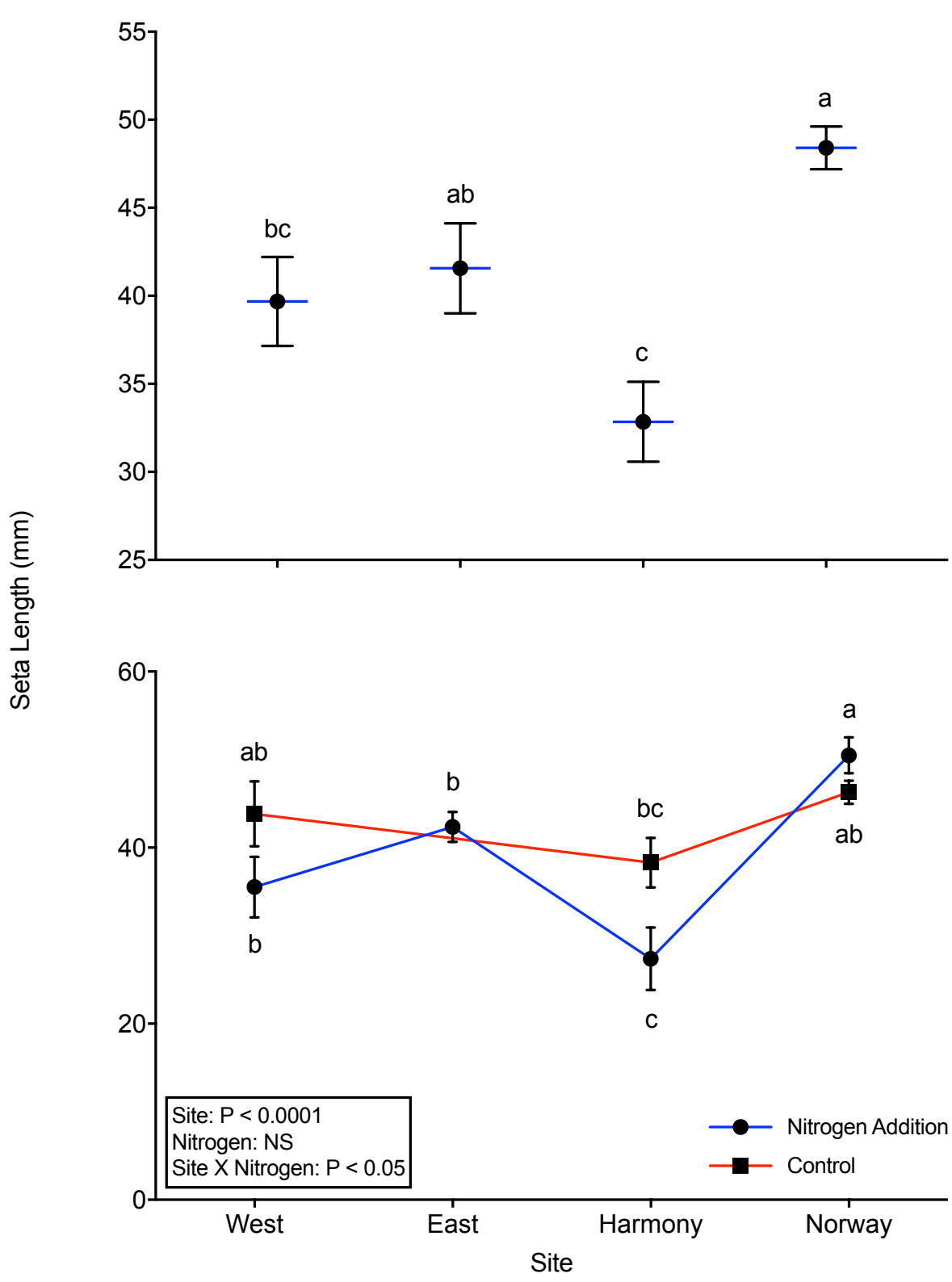

Figure 5: Least squared means ( \pm standard error) of seta length $(\mathrm{mm})$ of $P$. juniperinum based on full model comparing site (primary succession sites West and East; secondary succession sites Harmony and Norway), treatment (nitrogen addition VS control) and interaction between the two variables $(\mathrm{DF}=5 ; \mathrm{F}=6.5108 ; \mathrm{P}<0.0001)$. A) Effect test results from site only $(\mathrm{DF}=2 ; \mathrm{F}=15.8537 ; \mathrm{P}<.0001)$ and $\mathrm{B})$ results from interaction $(\mathrm{DF}=2 ; \mathrm{F}=4.3255 ; \mathrm{P}=0.0152)$. Levels not connected by same letter are significantly different based on Tukey's HSD. 
A.

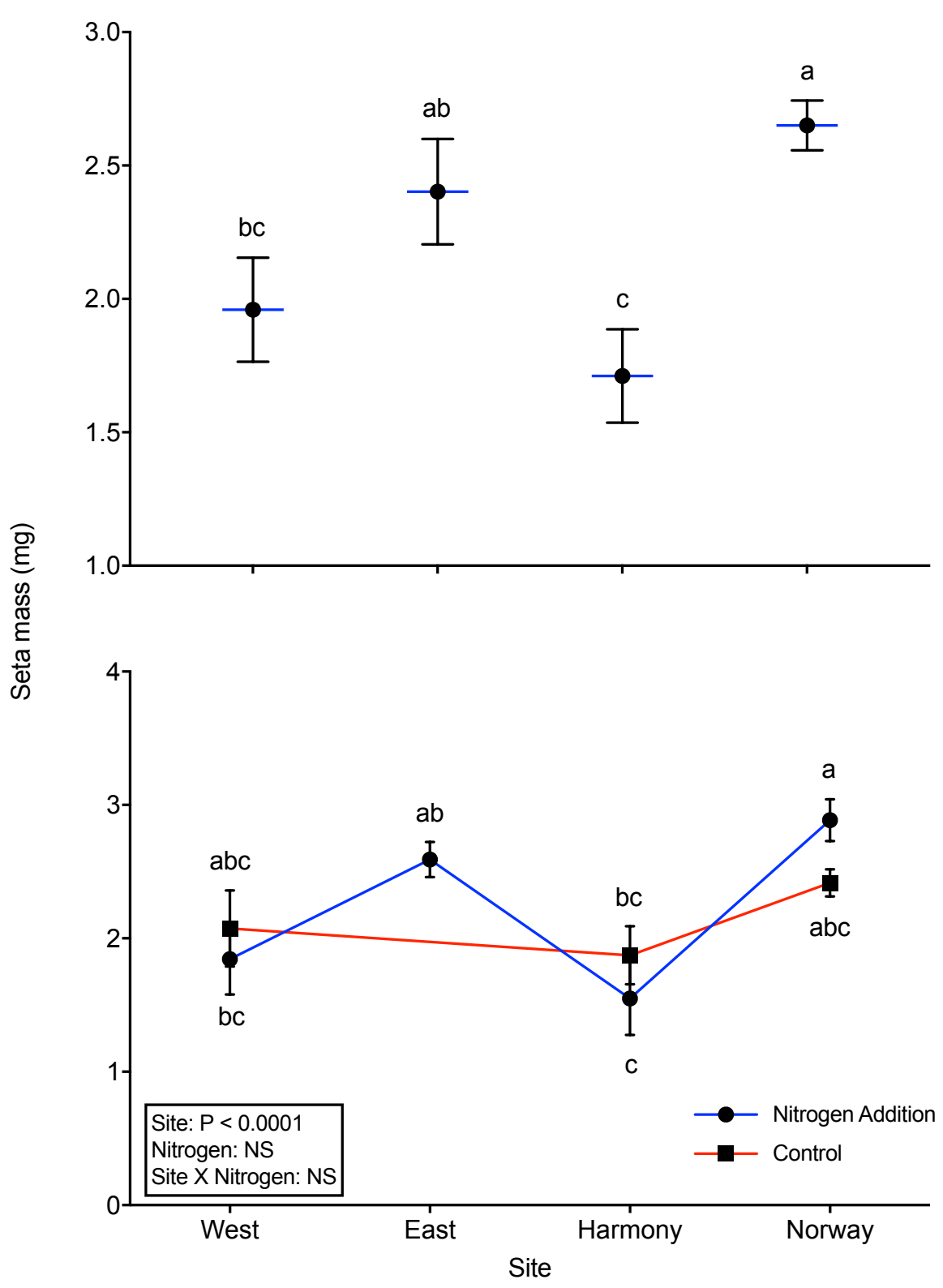

Figure 6: Least squared means ( \pm standard error) of seta mass $(\mathrm{mg})$ of $P$. juniperinum based on full model comparing site (primary succession sites West and East; secondary succession sites Harmony and Norway), treatment (nitrogen addition VS control) and interaction between the two variables $(\mathrm{DF}=5 ; \mathrm{F}=6.5108 ; \mathrm{P}<0.0001)$. A) Effect test results from site only $(\mathrm{DF}=2 ; \mathrm{F}=15.8537 ; \mathrm{P}<.0001)$ and B) results from interaction $(\mathrm{DF}=2 ; \mathrm{F}=4.3255 ; \mathrm{P}=0.0152)$. Levels not connected by same letter are significantly different based on Tukey's HSD. 


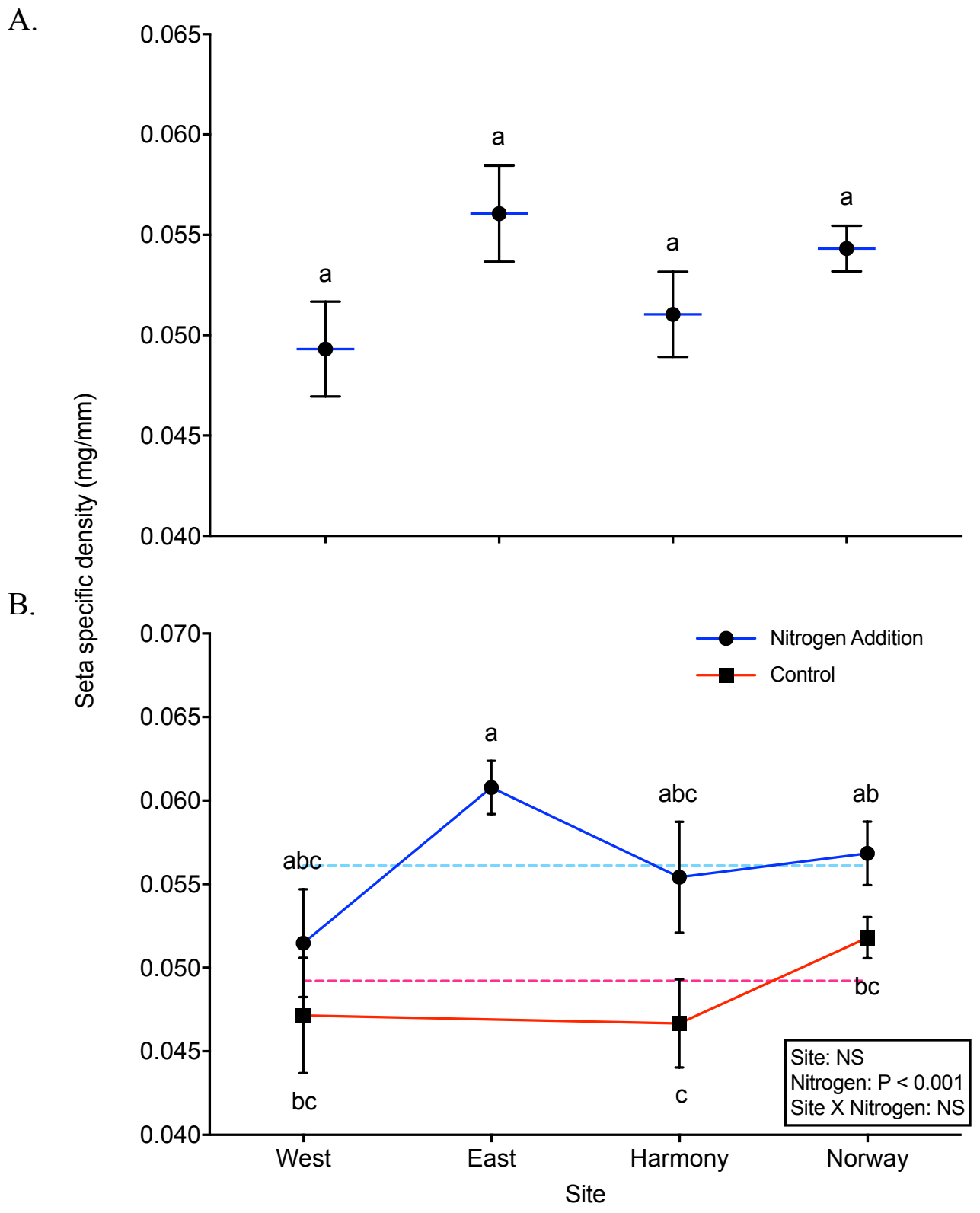

Figure 7: Least squared means ( \pm standard error) of seta specific density (SSD; $\mathrm{mg} / \mathrm{mm}$ ) of $P$. juniperinum based on full model comparing site (primary succession sites West and East; secondary succession sites Harmony and Norway), treatment (nitrogen addition VS control) and interaction between the two variables $(\mathrm{DF}=5 ; \mathrm{F}=6.8894 ; \mathrm{P}<0.0001)$. A) Effect test results from site only ( $\mathrm{DF}=2$; $\mathrm{F}=2.0846 ; \mathrm{P}=0.1285)$ and $\mathrm{B})$ results from nitrogen treatment $(\mathrm{DF}=1 ; \mathrm{F}=9.8117 ; \mathrm{P}=0.0021)$ and interaction $(\mathrm{DF}=2 ; \mathrm{F}=0.4399 ; \mathrm{P}=0.64514)$. Levels not connected by same letter are significantly different based on Tukey's HSD. Dashed lines represent treatment only means. 
A.

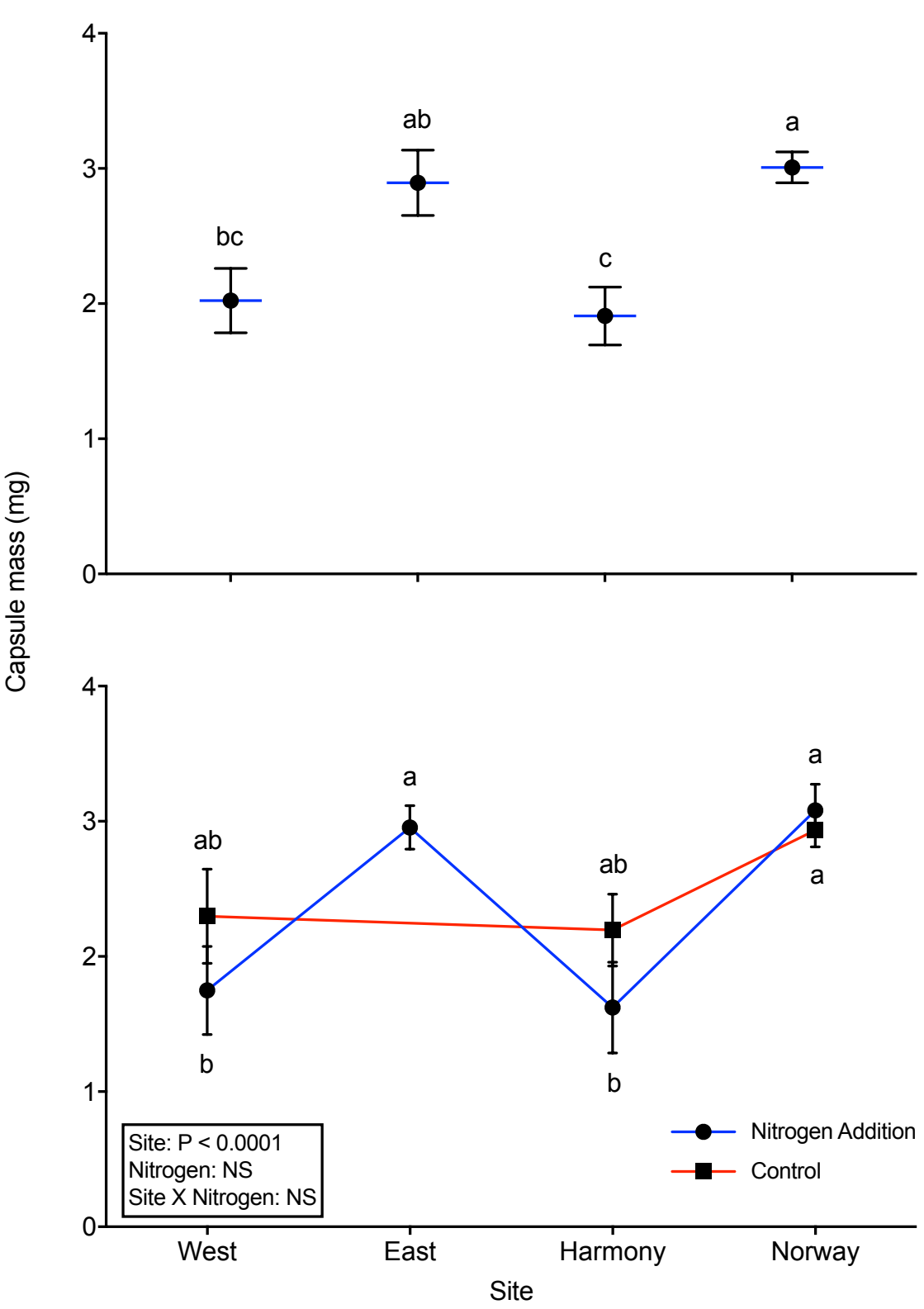

Figure 8: Least squared means ( \pm standard error) of capsule mass $(\mathrm{mg})$ of $P$. juniperinum based on full model comparing site (primary succession sites West and East; secondary succession sites Harmony and Norway), treatment (nitrogen addition VS control) and interaction between the two variables $(\mathrm{DF}=5 ; \mathrm{F}=4.8407 ; \mathrm{P}=0.0004)$. A) Effect test results from site only $(\mathrm{DF}=2 ; \mathrm{F}=10.9416$; $\mathrm{P}<0.0001)$ and $\mathrm{B})$ results from nitrogen treatment $(\mathrm{DF}=2 ; \mathrm{F}=0.9215 ; \mathrm{P}=0.3389)$ and interaction $(\mathrm{DF}=2 ; \mathrm{F}=1.2621 ; \mathrm{P}=0.28650)$. Levels not connected by same letter are significantly different based on Tukey's HSD. 
A.

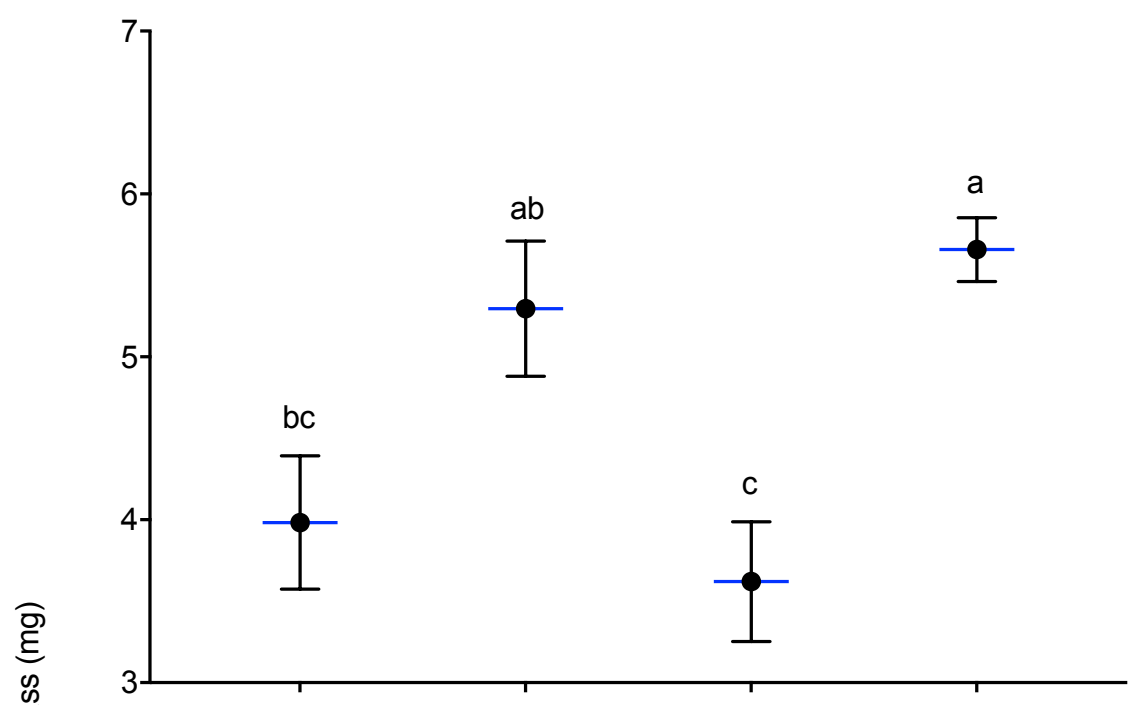

B.

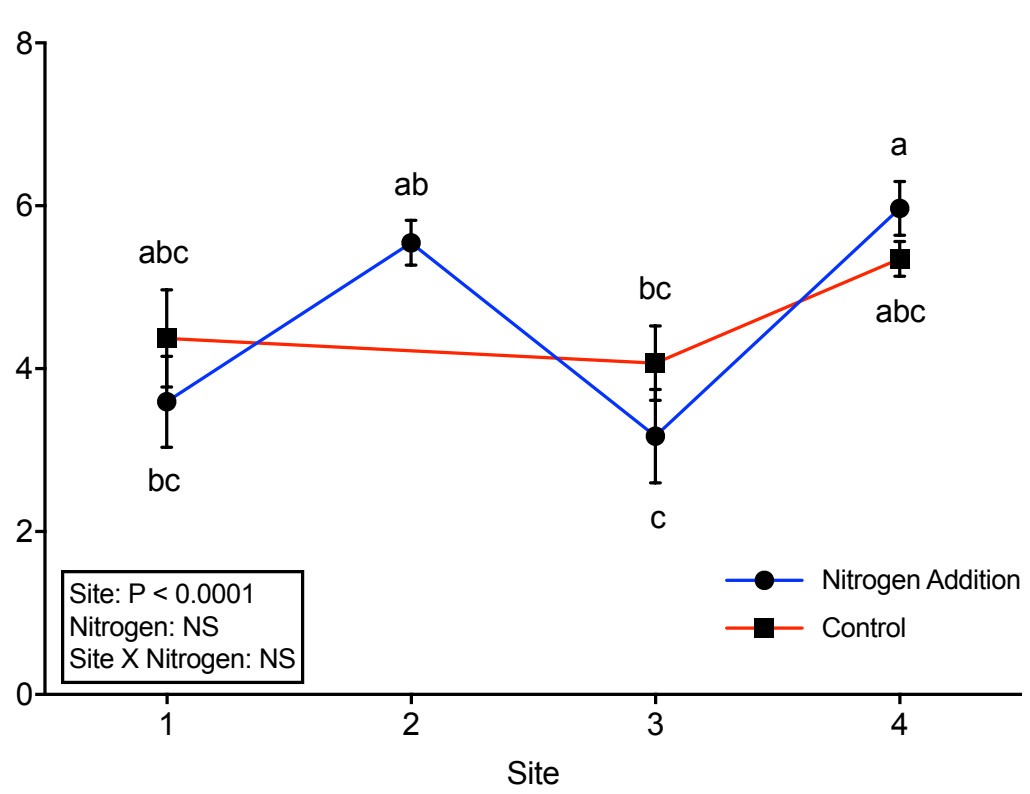

Figure 9: Least squared means ( \pm standard error) of total sporophyte mass $(\mathrm{mg})$ of $P$. juniperinum based on full model comparing site (primary succession sites West and East; secondary succession sites Harmony and Norway), treatment (nitrogen addition VS control) and interaction between the two variables $(\mathrm{DF}=5 ; \mathrm{F}=4.8407 ; \mathrm{P}=0.0004)$. A) Effect test results from site only ( $\mathrm{DF}=2 ; \mathrm{F}=10.9416$; $\mathrm{P}<0.0001)$ and $\mathrm{B})$ results from nitrogen treatment $(\mathrm{DF}=2 ; \mathrm{F}=0.9215 ; \mathrm{P}=0.3389)$ and interaction $(\mathrm{DF}=2 ; \mathrm{F}=1.2621 ; \mathrm{P}=0.28650)$. Levels not connected by same letter are significantly different based on Tukey's HSD. 
A.

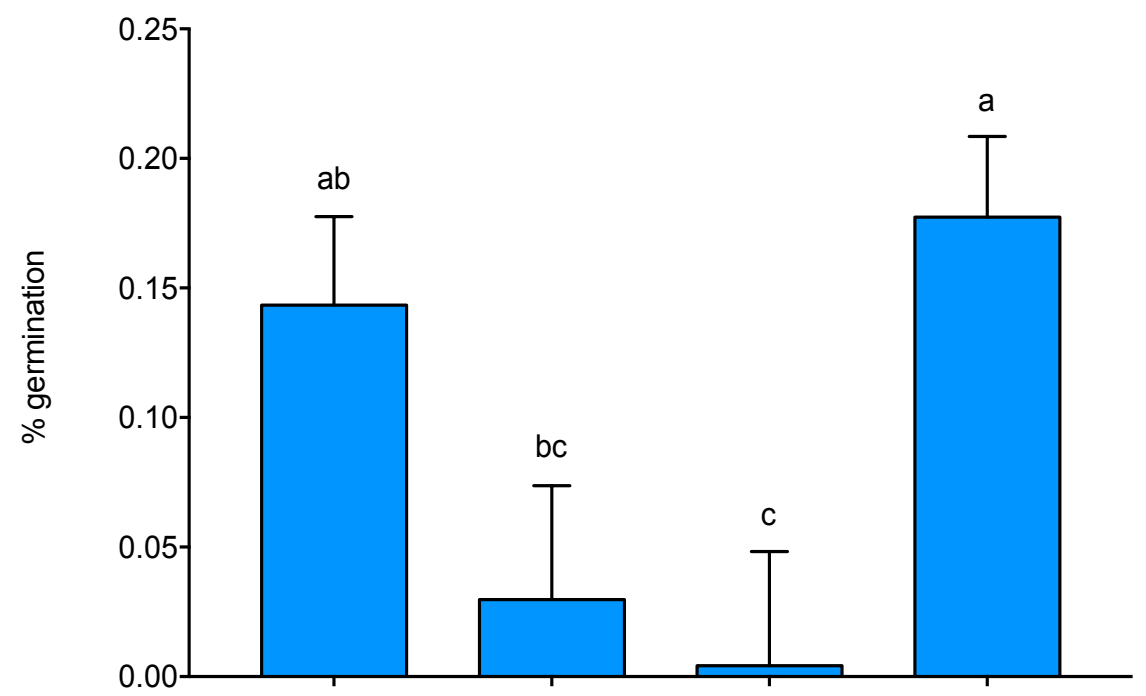

B.

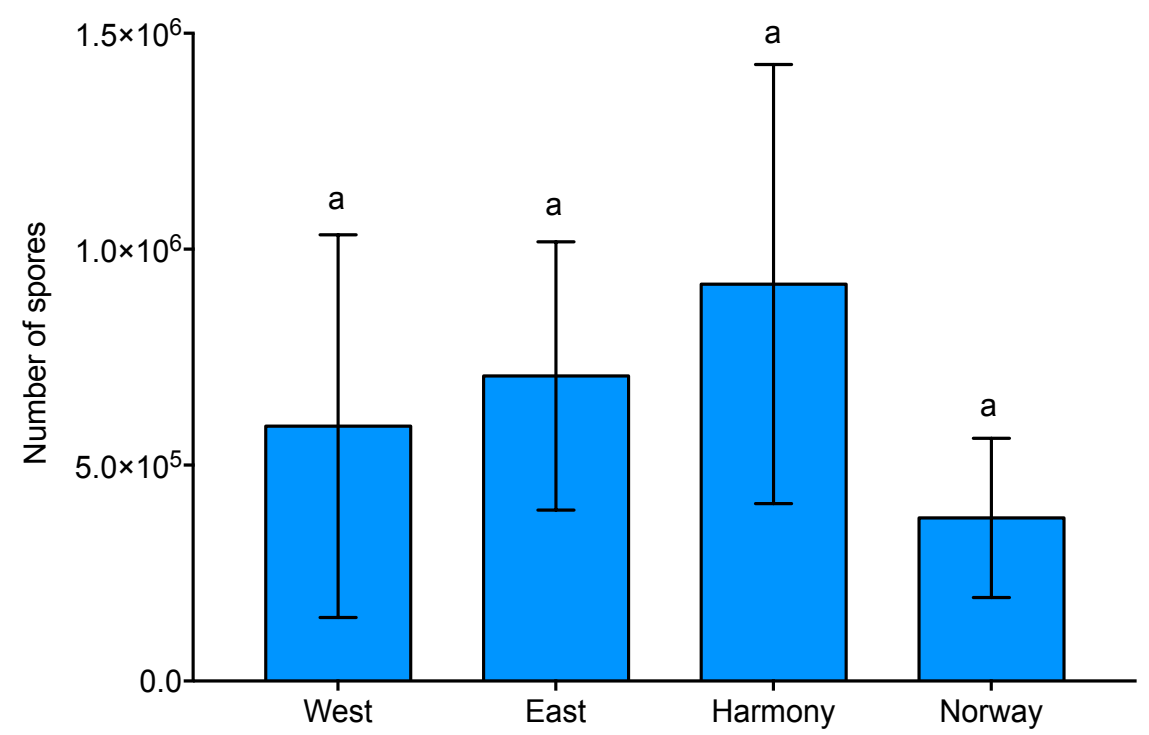

Figure 10: Least squared means ( \pm standard error) of A) maximum spore germination as a percent of the total count and B) total spore count per capsule of $P$. juniperinum by site (primary succession sites West and East; secondary succession sites Harmony and Norway). Levels not connected by same letter are significantly different based on Tukey's HSD. 
A.

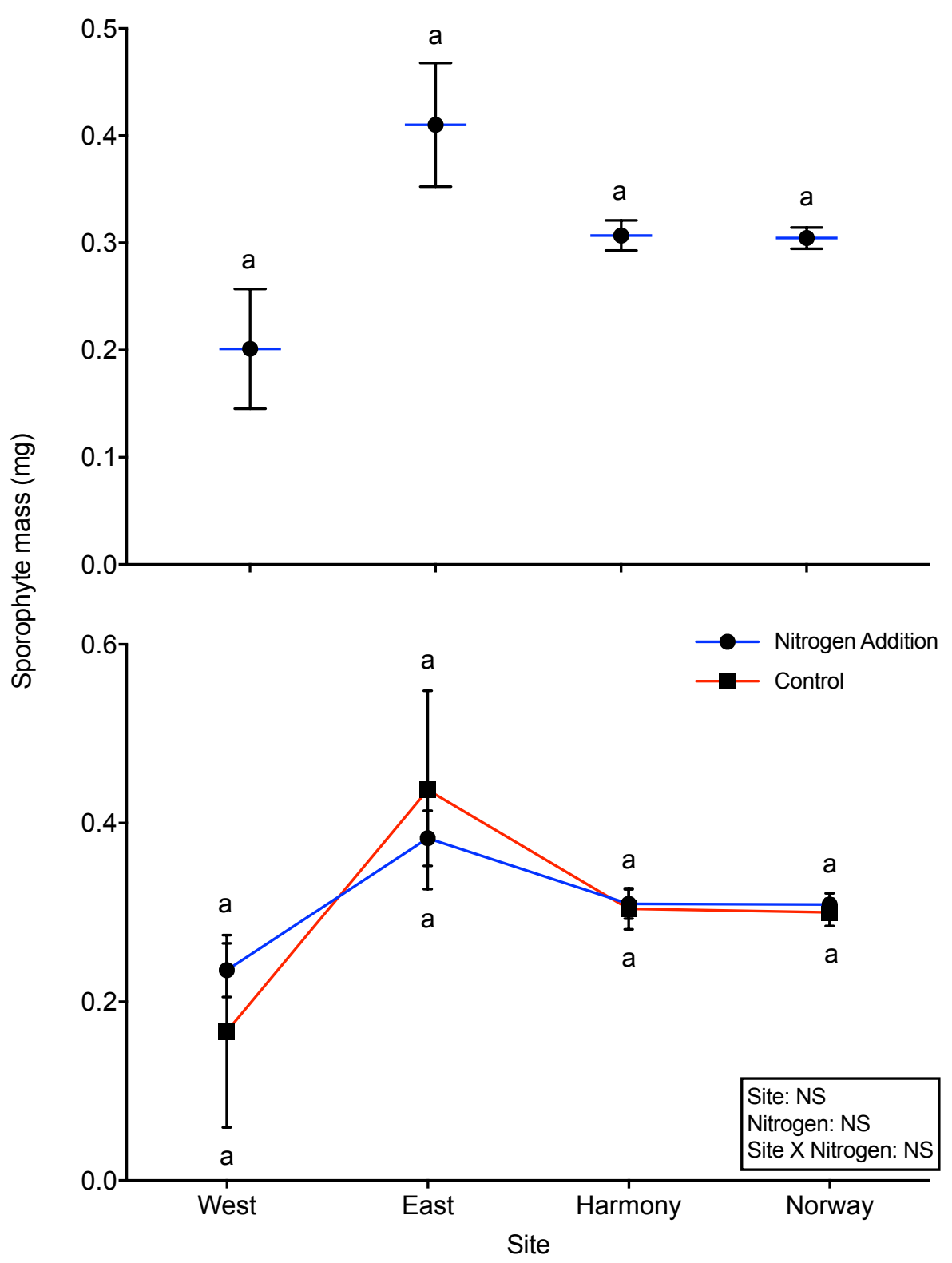

Figure 11: Least squared means ( \pm standard error) of total sporophyte mass (mg) of C. purpureus based on full model comparing site (primary succession sites West and East; secondary succession sites Harmony and Norway), treatment (nitrogen addition VS control) and interaction between the two variables ( $\mathrm{DF}=5 ; \mathrm{F}=1.6836 ; \mathrm{P}=0.1403)$. A) Effect test results from site only ( $\mathrm{DF}=2 ; \mathrm{F}=1.7349$; $\mathrm{P}=0.1792)$ and $\mathrm{B})$ results from nitrogen treatment $(\mathrm{DF}=1 ; \mathrm{F}=0.1749 ; \mathrm{P}=0.6763)$ and interaction $(\mathrm{DF}=2 ; \mathrm{F}=0.1518 ; \mathrm{P}=0.8593)$. Levels not connected by same letter are significantly different based on Tukey's HSD. 
A.

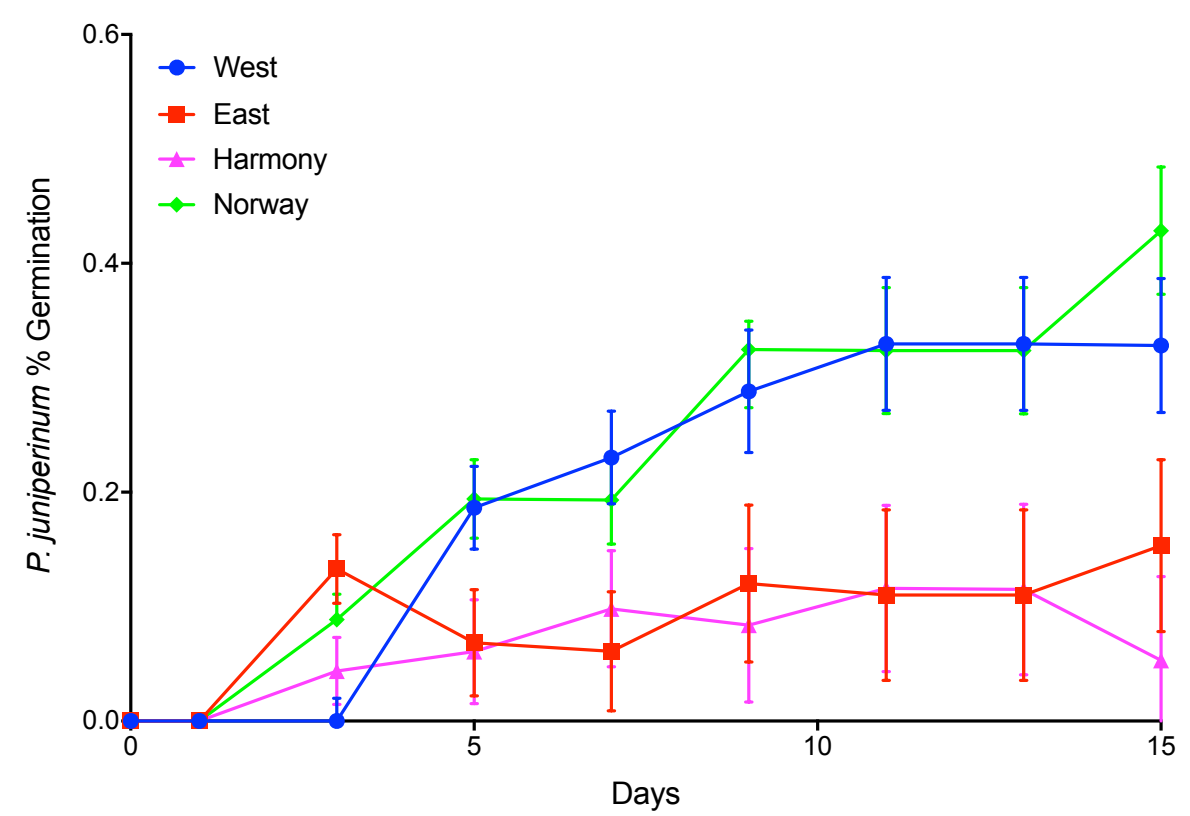

B.

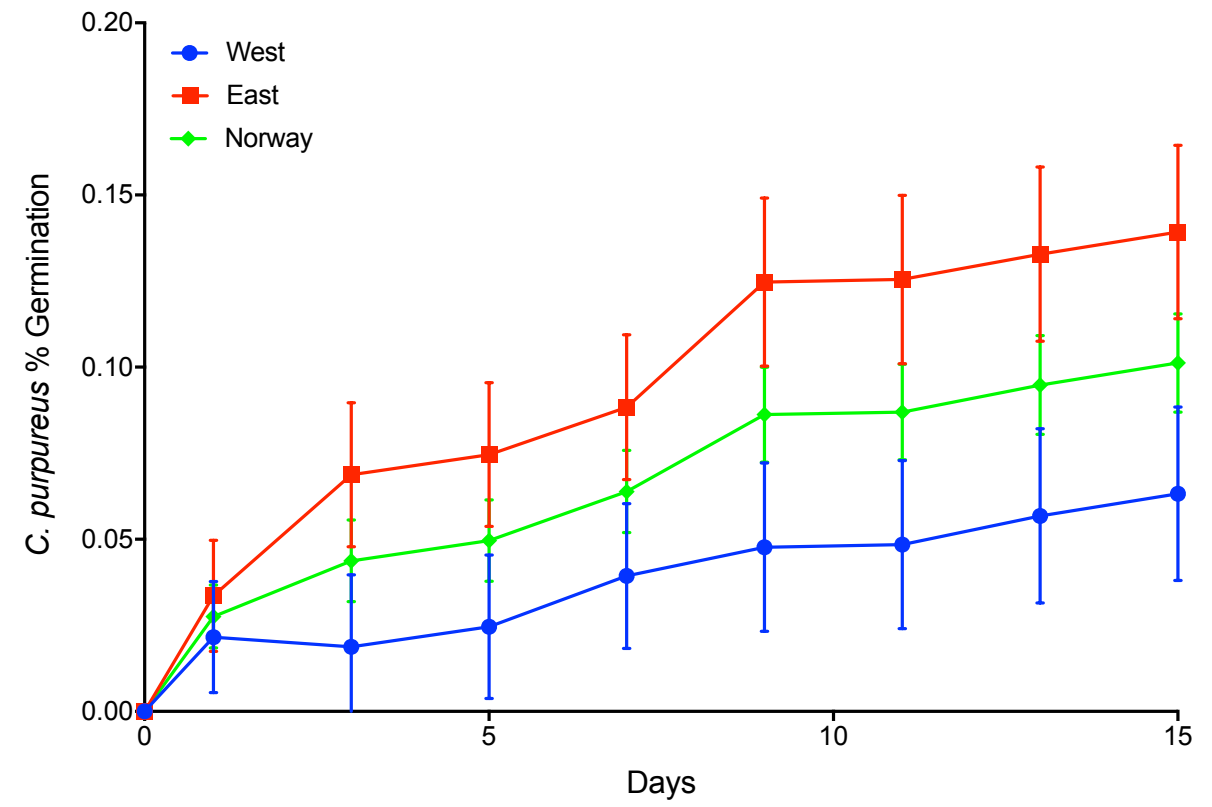

Figure 13: Least squared means ( \pm standard error) of arcsine transformed data of A) $P$. juniperinum and B) C. purpureus $\%$ of total spores germinated per day by site (primary succession sites West and East; secondary succession sites Harmony and Norway). 


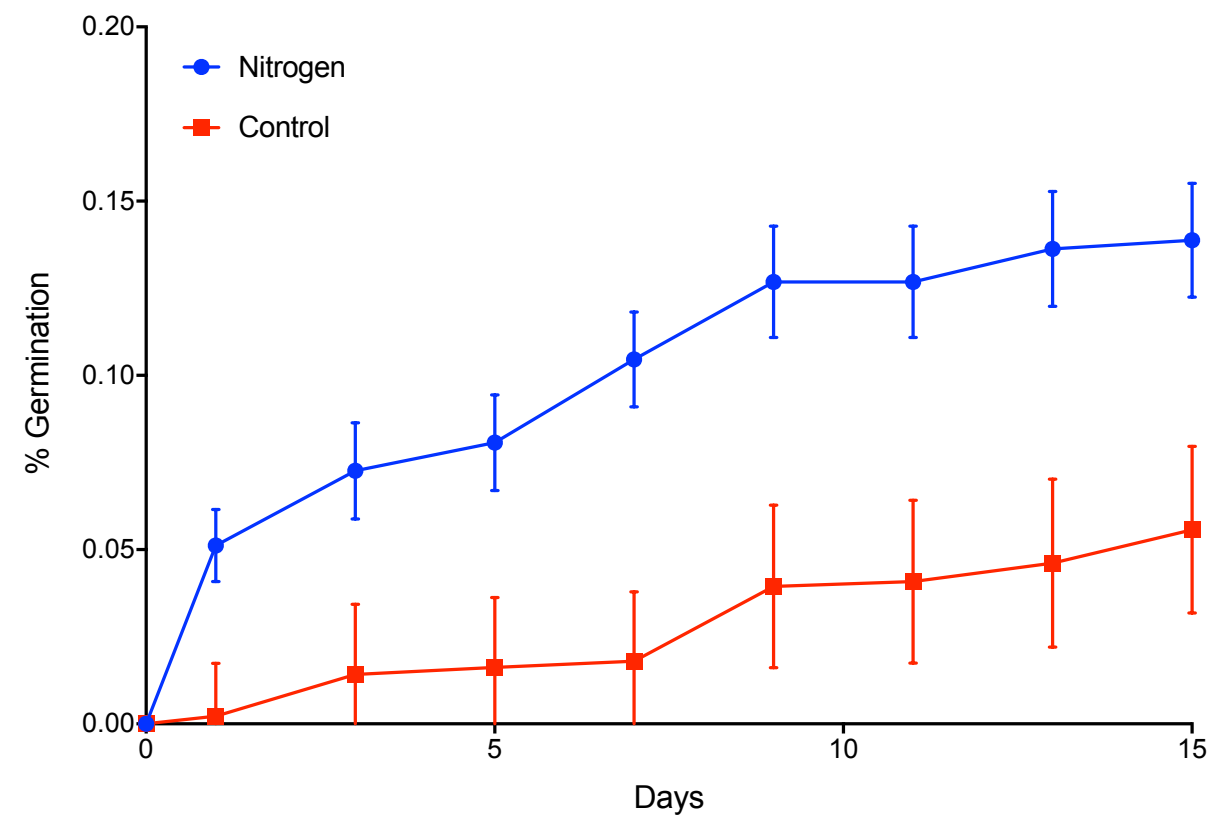

Figure 14: Least squared means ( \pm standard error) of arcsine transformed data of C. purpureus $\%$ of total spores germinated per day by plot treatment. 


\section{TABLES}

Table 1. The effects of environment (four sites), nitrogen treatment (treatment versus control), and the interaction between site and nitrogen treatment on morphological response in two moss species using ANOVA with Bonferroni correction. Significant results in bold.

\begin{tabular}{|c|c|c|c|c|c|c|c|}
\hline & \multirow[b]{2}{*}{$\mathrm{df}^{\mathrm{a}}$} & \multicolumn{2}{|c|}{ Site } & \multicolumn{2}{|c|}{ N Treatment } & \multicolumn{2}{|c|}{ Site x N } \\
\hline & & $\mathrm{F}$ & $P$ & $\mathrm{~F}$ & $P$ & $\mathrm{~F}$ & $P$ \\
\hline \multicolumn{8}{|l|}{ Polytrichum juniperinum } \\
\hline Gametophyte length & 129 & 6.898 & 0.013 & 1.880 & 0.518 & 3.663 & 0.085 \\
\hline Gametophyte mass & 129 & 4.937 & 0.026 & 0.747 & 1.000 & 1.115 & 0.994 \\
\hline Gametophyte specific density & 129 & 1.898 & 0.462 & 0.164 & 1.000 & 0.445 & 1.000 \\
\hline Calyptra mass & 129 & 6.909 & 0.004 & 0.666 & 1.000 & 3.055 & 0.152 \\
\hline Seta length & 129 & 15.854 & $<0.001$ & 2.039 & 0.467 & 4.326 & 0.046 \\
\hline Seta mass & 129 & 10.453 & $<0.001$ & 0.165 & 1.000 & 2.108 & 0.377 \\
\hline Capsule mass & 129 & 10.942 & $<0.001$ & 0.922 & 1.000 & 1.262 & 0.860 \\
\hline Total sporophyte mass & 129 & 11.965 & $<0.001$ & 0.134 & 1.000 & 1.814 & 0.502 \\
\hline Seta specific density & 129 & 2.085 & 0.386 & 9.812 & 0.006 & 0.440 & 1.000 \\
\hline Reproductive effort & 129 & 1.945 & 0.441 & 2.148 & 0.435 & 1.045 & 1.000 \\
\hline Spore count & 40 & 0.650 & 1.000 & 0.286 & 1.000 & 1.972 & 0.458 \\
\hline Maximum germination & 31 & 6.019 & 0.019 & 0.059 & 1.000 & 0.654 & 1.000 \\
\hline \multicolumn{8}{|l|}{ Ceratodon purpureus } \\
\hline Total sporophyte mass & 192 & 1.735 & 0.538 & 0.175 & 1.000 & 0.152 & 1.000 \\
\hline Spore count & 22 & 0.984 & 1.000 & 0.001 & 1.000 & 0.000 & 1.000 \\
\hline Maximum germination & 51 & 1.300 & 0.779 & 4.979 & 0.090 & $\mathrm{~b}$ & $\mathrm{~b}$ \\
\hline
\end{tabular}

${ }^{\mathrm{a}}$ Within groups degrees of freedom.

${ }^{\mathrm{b}}$ Missing data from the Harmony site resulted in lost df's for this test

Table 2. Repeated measures MANOVA on \% germination of total spore counts over time, site, $\mathrm{N}$-addition and interaction. F test results unless otherwise noted.

\begin{tabular}{|c|c|c|c|c|c|c|c|c|c|c|c|c|}
\hline & \multicolumn{3}{|c|}{ Time } & \multicolumn{3}{|c|}{ Time $\mathrm{x}$ Site } & \multicolumn{3}{|c|}{ Time $\mathrm{x} N$ addtition } & \multicolumn{3}{|c|}{ Time $\mathrm{x} \mathrm{N}$ addtion $\mathrm{x}$ Site } \\
\hline & $\mathrm{df}$ & $\mathrm{F}$ & $P$ & $\mathrm{df}$ & $\mathrm{F}$ & $P$ & $\mathrm{df}$ & $F$ & $P$ & $\mathrm{df}$ & $\mathrm{F}$ & $P$ \\
\hline C. purpureus & 44 & 7.4527 & $<.0001$ & 44 & 3.4247 & 0.0038 & 44 & 4.438 & 0.0005 & $\mathrm{~b}$ & $\mathrm{~b}$ & $\mathrm{~b}$ \\
\hline P. juпiperinum & 24 & 2.5006 & 0.0393 & $48^{\mathrm{a}}$ & $4.2254^{\mathrm{a}}$ & $<.0001^{\mathrm{a}}$ & 24 & 1.5426 & 0.195 & $48^{\mathrm{a}}$ & $2.4362^{\mathrm{a}}$ & $0.0089^{\mathrm{a}}$ \\
\hline
\end{tabular}




\section{Chemical inhibition of germination by mosses}

\section{INTRODUCTION}

Mosses are some of the first colonizers on volcanic substrates (Delgadillo and Cardenas 1995) though the role of mosses in primary succession beyond assumptions of net primary production, biomass accumulation, and moisture/thermal regulation is not fully understood (Turetsky et al. 2010). Additionally, the genetic by environmental interactions influencing competition or facilitation in during germination and initial growth in any system remain elusive (Firbank and Watkinson 1990; Goldberg 1990; Meiners et al. 2013). Though mosses have been observed facilitating the germination of vascular plants in secondary succession systems (Delach and Kimmerer 2002; Vincent, Lawlor, and Tipping 2001; Nilsson, Steijlen, and Zackrisson 1996), it is largely unknown to what extent mosses compete with other moss spores or tracheophyte seeds during dispersal and germination in systems undergoing primary succession. Regional-level studies have demonstrated that mosses can physically compete with neighboring plants by sequestering and reducing availability of mineral nutrients and by reducing recruitment of seeds and seedlings by shading and competing for space (Oechel and Van Cleve 1986). However studies of potential for chemical-mediated competition- through negative effects on neighboring plant seed germination and radicle growth are lacking (Michel, Burritt, and Lee 2011) - but needed if we are to understand more fully the interspecific effects mosses have during primary succession.

Though an important factor that may affect establishment, chemical-mediated competition has been difficult to show under field conditions (Meiners et al. 2013). Many chemical competition studies that have focused on seed and seedling interactions have 
been confined to vascular plants in agricultural or forestry systems (Williamson 1990). Few have focused on interactions of the equivalent spore and protonemal stage of nonvascular plants and even fewer on the chemical ecology of bryophytes as an important community-structuring guild. Since mosses do experience herbivory (Thomas and Lombard 1991) and have coevolved with bacteria and fungi they exhibit defensive chemicals compounds like many of their tracheophyte relatives (Asakawa 2001; 2007; 2011; Asakawa, Ludwiczuk, and Nagashima 2013). The level to which such chemicals are constitutive or inducible and whether levels change with environmental or biologic stress remains an active area of study.

Specific moss compounds inhibiting seed germination and root and shoot development have been isolated: 3-hydroxy-b-ionone, a rose ketone derived from the degradation of carotenoids, was isolated from the moss Rhynchostegium pallidifolium and inhibited tracheophyte growth (Kato-Noguchi, Seki, and Shigemori 2010). Momalactone $\mathrm{a}$ and $\mathrm{b}$, diterpenes isolated and determined by MS and 1H- and 13C-NMR spectral data from Hypnum plumaeforme, inhibited tracheophyte roots and shoots (KatoNoguchi, Kobayashi, and Shigemori 2009). Methanol extractions from mosses have been shown to inhibit spore germination and protonemal development of Tortula species under lab conditions (Sorbo, Basile, and Cobianchi 2004). Mishler and Newton (1988) found that a distilled water solution from soaking Dichranum patches for 24 hours inhibited the germination of Tortula spores and reduced protonemal radii. If these compounds evolved to restrict the growth of neighboring plants studies into their function must take into account the ecological context under which the traits were selected, namely, water solubility, natural concentrations, and timing. 
As an initial study to determine moss species effects on the primary succession of MSH, I used three predominant mosses found there and one dominant tracheophyte to test for inter- and intraspecies effects between moss gametophytes and spores and seeds under more natural conditions. The purpose of this experiment was to determine whether 1) a germination-inhibiting compound is produced by the mosses of MSH during plant establishment and 2) if stress increases its effect/prodcution. I hypothesized that if putative inhibitory chemicals are induced to a greater extent under water, temperature and/or nutrient stress, an increase in competition under stress could be measured by differences in spore and seed germination rate.

\section{METHODS}

\section{Spore germination}

Spores from C. purpureus and P. juniperinum were collected as described above. Gametophyte turf patches were collected from $R$. canescens and $P$. juniperinum populations from primary and secondary zones and were kept on sterile pumice in a greenhouse. Infusions of the gametophyte turfs were made by first ceasing irrigation for 14 days and then soaking $5-\mathrm{x}-5 \mathrm{~cm}$ turfs of $\sim 25 \mathrm{~g}$ of each species in $100 \mathrm{~mL}$ of sterile tap water for $24 \mathrm{~h}$. Infusions were run through filter paper and autoclaved at $120^{\circ} \mathrm{C}$. Spore slurry from each capsule was diluted to a concentration of $12.5 \%$ of original concentration. $25 \mathrm{~mL}$ of slurry were mixed with $75 \mathrm{~mL}$ of the infusion or sterile tap water, and five replicates of each capsule were plated on petri dishes with sterile agar. Dishes were kept in a grow room with a $12 \mathrm{~h}$ light/dark cycle and ambient temperature of $25^{\circ} \mathrm{C}$. Germination was estimated every 2 days for 16 days by counting germinated 
spores, defined as elongation of the spore due to cell division, along a random transect across the agar plate at $100 \mathrm{X}$ magnification. Percentages were calculated as a ratio of spores germinated per capsule per day over total spores per capsule.

\section{Lupine germination}

Lupinus lepidus seeds collected in June 2015 from the primary succession zone of $\mathrm{MSH}$ and kept under $1.5^{\circ} \mathrm{C}$ refrigeration for a minimum of 2 weeks were sown either in patches of $R$. canescens placed on $2.5 \mathrm{~cm}$ deep trays containing gardener's perlite or directly on perlite and kept under natural sunlight and temperature in a research greenhouse. Each tray was automatically irrigated with a mister system using tap water for 10 minutes every day. Seedlings were harvested after 150 days and morphological traits were measured: presence/absence of seedlings, number of true leaves, number or root branches, wet length from tip of tap root to apical meristem, wet mass, and dry mass after seven days at $50^{\circ} \mathrm{C}$. Two replications of 20 seeds in each treatment were assayed. Statistical analysis - To analyze the effects of spore plot of origin factors and germination infusion treatment on percent of total spore count germinated over time, germination data were analyzed using a repeated measures MANOVA. Proportion data were arcsine transformed before analysis to correct for a non-binomial distribution. Tukey's post hoc analyses were used to determine significant differences among factors. Chi squared tests were used for presence/absence of lupine seedlings on the two substrata. All analyses were performed using JMP Pro (version 12.0.1, 2015 SAS Institute Inc.). 


\section{RESULTS}

\section{Spore germination}

No significant differences between infusion type were detected in either species germinated. In C. purpureus a pattern of repressed germination in both infusion treatment groups is apparent as compared to spores in the control group (Figure 15). Though regression analysis showed slopes between treatments were significantly different $(\mathrm{F}$ $=18.41 . \mathrm{DFn}=2, \mathrm{DFd}=21, P<0.0001)$, germination differences by treatment can not be separated from the germination differences associated with site of origin and nitrogen addition plots (Table 3).

\section{Lupine germination}

Chi squared tests showed significant differences in lupine germination based on treatment $(P<0.05)$. If expected maximum germination was 50\% (Endo et al. 1981), then moss patches significantly reduced germination of lupine seed, with germination on moss patches at $30 \%$ versus $55 \%$ on bare pumice. Though not statically significant, mean seedling mass, seedling length, number of true leaves and number of rootlets were all higher in those plants that did germinate and develop into seedlings on moss patches (Figure 16).

\section{DISCUSSION}

Factors effecting seed germination are complex, and the interactions are many (Elliott, Fischer, and LeRoy 2011). They include a suite of genetic and environmentally contingent cues to maximize success of future generations in varying conditions (Violle 
et al. 2009). Certain plants have evolved to limit the germination of neighboring plants by exuding chemical compounds into the soil from their root systems, or through the deposition and decomposition of their leaf litter (Weir, Park, and Vivanco 2004). The leafy gametophyte of bryophytes may also have evolved the means to chemically inhibit the germination of competing plant propagules that disperse into their populations, including seeds from neighboring angiosperms and conifers, as well as the spores of cooccurring bryophytes (Mishler and Newton 1988). Inhibitory compounds have been isolated in mosses and lichens, and may have evolved to reduce potential resource competition (Kato-Noguchi, Kobayashi, and Shigemori 2009; Kato-Noguchi, Seki, and Shigemori 2010; Sorbo, Basile, and Cobianchi 2004). Though chemical compounds were not isolated in this study, $P$. juniperinum and $R$. canescens may be able to inhibit the germination of incoming moss spores with water soluble exudates from their gametophytic tissue.

The reduction of germination observed here at all time points measured in $C$. purpureus, and in the first critical time points in P. juniperinum highlights an intriguing pattern in the ability of established moss gametophytes to potentially slow the germination of incoming spores under natural conditions. In a successional landscape the ability to quickly establish is related to a plant's ability to outcompete neighbors for resources (Weinig 2000). Mosses may be employing a strategy limiting competition from other mosses on MSH. In order to assess if mosses are able to compete against early establishing tracheophytes, moss patch effects on the $\mathrm{N}$-fixing legume L. lepidus were also observed. 
The widespread moss $R$. canescens may be able to inhibit the germination of seeds in L. lepidus on MSH, either with the same or similar chemical exudates that may limit moss spores, or by physical means, i.e. shading. The significant reduction of seed germination in moss patches in my experiment has far reaching implications for the successional trajectory of this volcanic system. The importance of lupines in primary successional landscapes can not be understated (Bishop 2002; Titus 2009; Hiltbrunner et al. 2014). Though lupines on moss patches may be out-performing plants germinated on bare ground once established, ultimate success depends on their ability to germinate. In future assessments on plant community development on MSH the interaction between these two species necessitates closer monitoring.

Mosses may be initiating an inhibition strategy on co-occurring moss and vascular plant spores and seeds, though if they are able to germinate, the environmental stress mitigation properties of moss patches may than help early plant development. Future studies should incorporate a greater number of replicates to determine if the patterns observed in this study are supported. Plant surveys that account for the occurrence and conditions around tracheophytes in moss patches will add a greater level of precision to projections of plant succession in volcanic landscapes. Further, chemical analyses of infusion solutions may reveal identifiable compounds already associated with germination limitation, namely, specific phenolic compounds that may disrupt a seed or spore's photosystems or mitochondria, the metabolic functions of which are imperative for successful germination (Weir, Park, and Vivanco 2004). These observations warrant more in depth observational and manipulative experiments into the complex interactions 
between mosses and other plants, with potentially greater incite into how these assemblages guide the successional trajectory of severely disturbed landscapes. 


\section{FIGURES}

A.

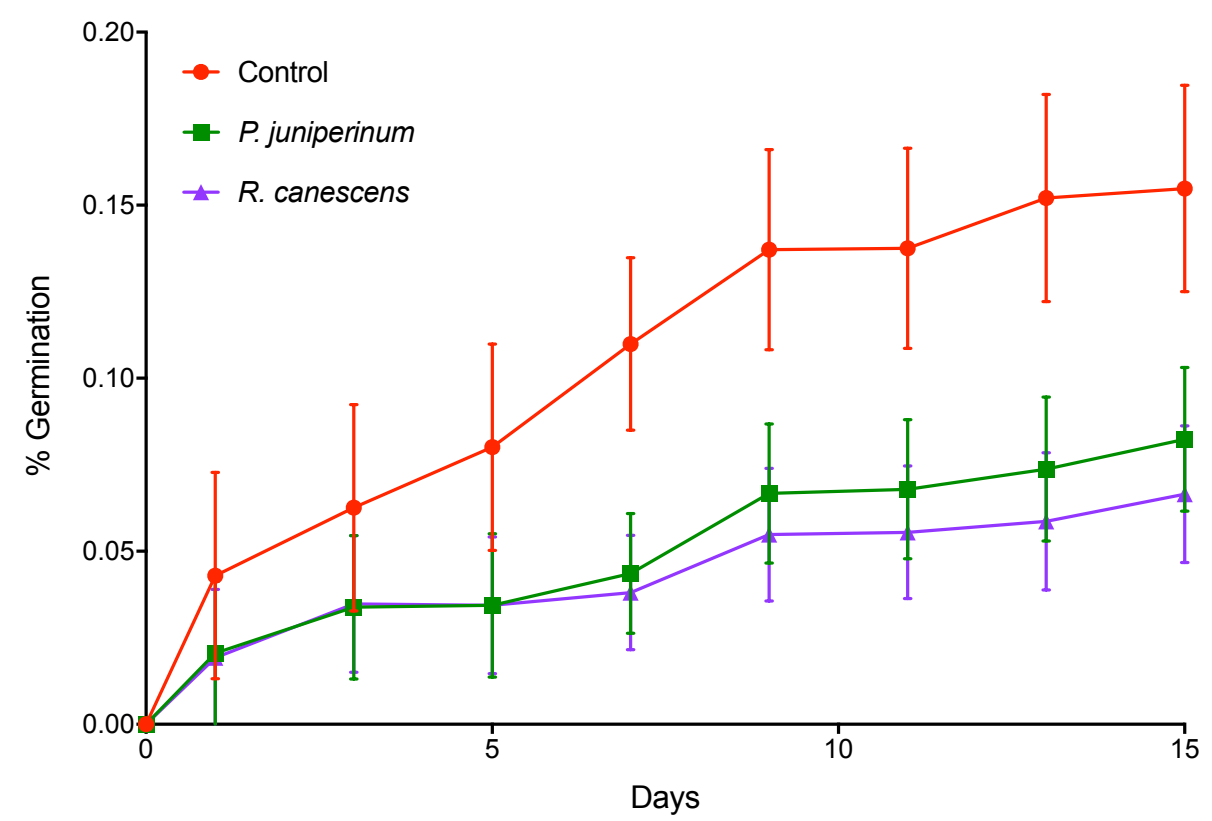

B.

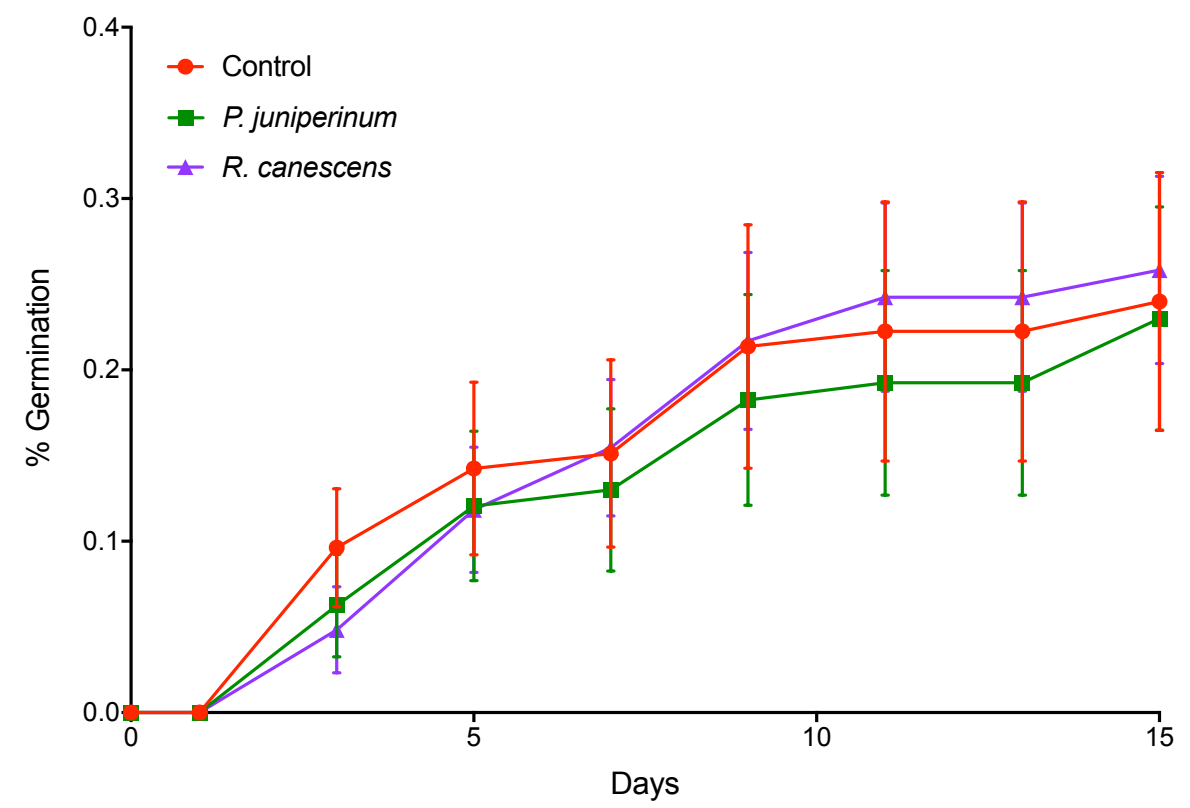

Figure 15: Least squared means ( \pm standard error) of arcsine transformed data of A) C. purpureus and B) P. juniperinum $\%$ of total spores germinated per day by treatment (control and infusions of $P$. juniperinum and $R$. canescens.) 
A.

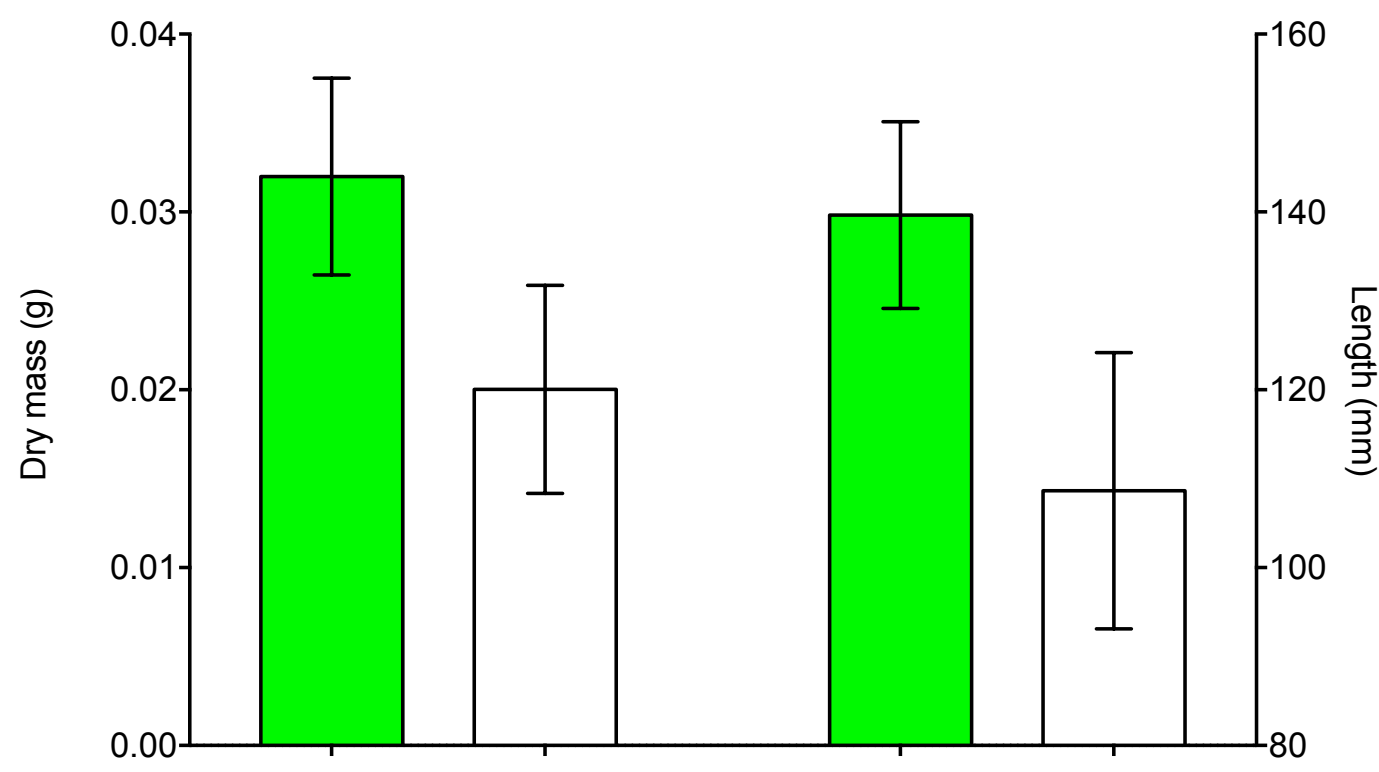

B.

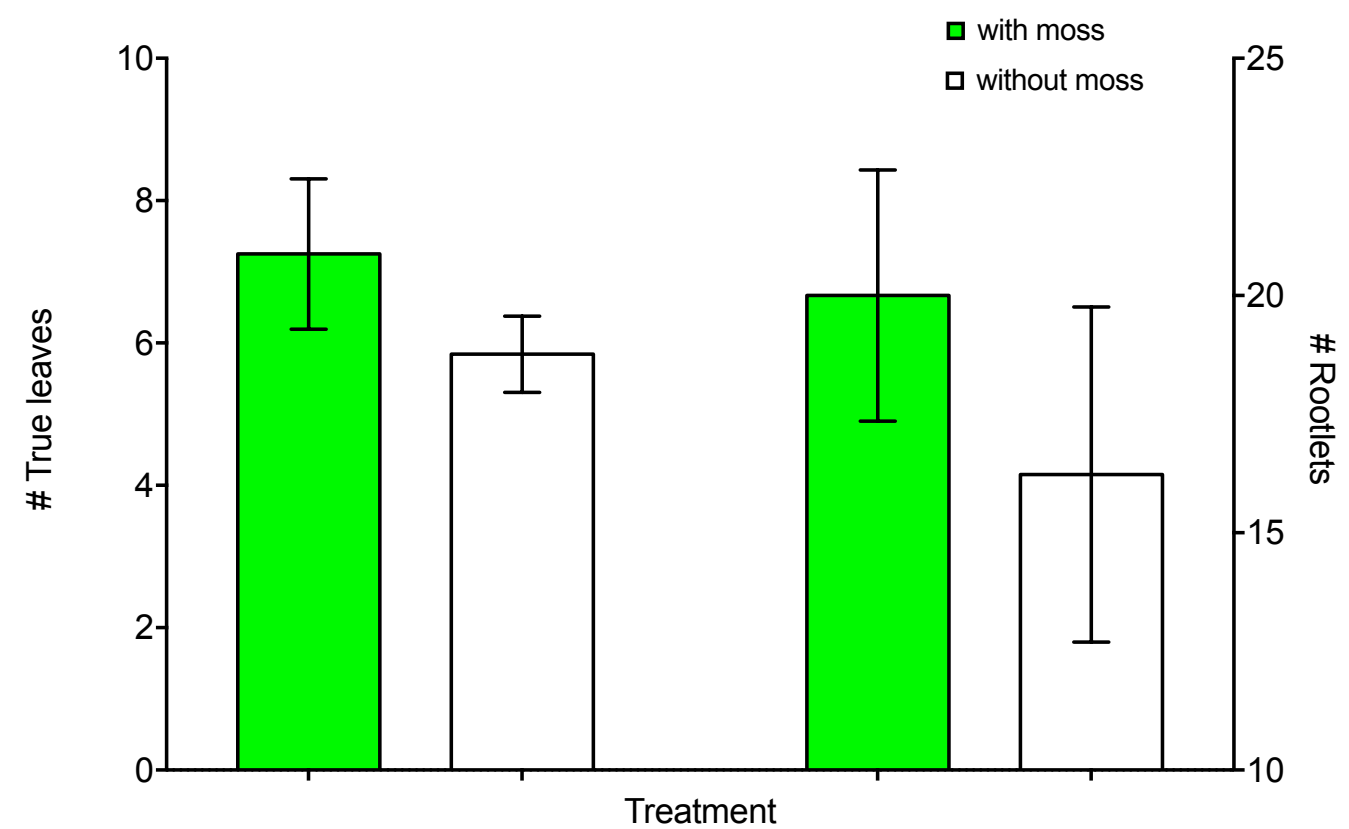

Figure 16: Mean ( \pm standard error) of Lupinus lepidus morphological measurements of seedlings germinated in moss patches and on bare pumice: A) Total seedling dry mass, B) Total seedling length, C) Number of true leaves, and D) Number of rootlets. 


\section{TABLES}

Table 3. Repeated measures MANOVA on \% germination of total spore counts over time, site and $\mathrm{N}$-addition of spore origin and infusion treatment. Significant results in bold.

\begin{tabular}{|c|c|c|c|c|c|c|c|c|c|c|c|c|}
\hline & \multicolumn{3}{|c|}{ Time } & \multicolumn{3}{|c|}{ Time $x$ Site } & \multicolumn{3}{|c|}{ Time $\mathrm{x} \mathrm{N}$ addition } & \multicolumn{3}{|c|}{$\begin{array}{c}\text { Time } \mathrm{x} \text { N addition } \mathrm{x} \\
\text { Site } \\
\end{array}$} \\
\hline & $\mathrm{df}$ & $\mathrm{F}$ & $P$ & $\mathrm{df}$ & $\mathrm{F}$ & $P$ & $\mathrm{df}$ & $\mathrm{F}$ & $P$ & $\mathrm{df}$ & $\mathrm{F}$ & $P$ \\
\hline C. purpureus & 38 & 8.8115 & $<.0001$ & 38 & 1.3638 & 0.2435 & 38 & 2796 & 0.0061 & $\mathrm{~b}$ & $\mathrm{~b}$ & $\mathrm{~b}$ \\
\hline \multirow[t]{5}{*}{ P. juniperinum } & 12 & 4.1686 & 0.0134 & $24^{\mathrm{a}}$ & 4.9081 & 0.0003 & 12 & 1314 & 0.4087 & $24^{\mathrm{a}}$ & 4966 & 0.0208 \\
\hline & \multicolumn{3}{|c|}{$\begin{array}{c}\text { Time } x \text { Infusion } \\
\text { Species }\end{array}$} & \multicolumn{3}{|c|}{$\begin{array}{c}\text { Time } \mathrm{x} \text { Infusion Species } \mathrm{x} \\
\text { Site }\end{array}$} & \multicolumn{3}{|c|}{$\begin{array}{c}\text { Time } \mathrm{x} \text { Infusion } \\
\text { Species } \mathrm{x} \mathrm{N} \text { addition }\end{array}$} & \multicolumn{3}{|c|}{$\begin{array}{c}\text { Time x Infusion species } \mathrm{x} N \\
\text { addition } \mathrm{x} \text { Site }\end{array}$} \\
\hline & $\mathrm{df}$ & $\mathrm{F}$ & $P$ & $\mathrm{df}$ & $\mathrm{F}$ & $P$ & $\mathrm{df}$ & $\mathrm{F}$ & $P$ & $\mathrm{df}$ & $\mathrm{F}$ & $P$ \\
\hline & 76 & 0.956 & 0.5117 & 76 & 0.9669 & 0.5002 & 76 & 1.1116 & 0.3602 & $\mathrm{~b}$ & $\mathrm{~b}$ & $\mathrm{~b}$ \\
\hline & $24^{\mathrm{a}}$ & 0.3551 & 0.9819 & $45.849^{\mathrm{a}}$ & 0.5529 & 0.9595 & $24^{\mathrm{a}}$ & 0.3344 & 0.9864 & $45.849^{\mathrm{a}}$ & 0.3383 & 0.9991 \\
\hline
\end{tabular}

a. Wilk's Lamda

b. Test excluded due to lost dfs 


\section{LITERATURE CITED}

Ackermann, Kathrin, Olle Zackrisson, Johannes Rousk, David L. Jones, and Thomas H. DeLuca. 2012. "N2 Fixation in Feather Mosses Is a Sensitive Indicator of N Deposition in Boreal Forests.” Ecosystems 15 (6): 986-98. doi:10.1007/s10021-0129562-y.

Asakawa, Y. 2007. "Biologically Active Compounds from Bryophytes." Pure and Applied Chemistry 79 (4): 557-80. doi:10.1351/pac200779040557.

Asakawa, Y. 2001. "Recent Advances in Phytochemistry of Bryophytes-Acetogenins, Terpenoids and Bis(bibenzyl)s from Selected Japanese, Taiwanese, New Zealand, Argentinean and European Liverworts." Phytochemistry. doi:10.1016/S00319422(00)00454-4.

Asakawa, Yoshinori. 2011. "Bryophytes: Chemical Diversity, Synthesis and Biotechnology. A Review." Flavour and Fragrance Journal. doi:10.1002/ffj.2060.

Asakawa, Yoshinori, Agnieszka Ludwiczuk, and Fumihiro Nagashima. 2013. "Phytochemical and Biological Studies of Bryophytes." Phytochemistry. doi:10.1016/j.phytochem.2012.04.012.

Bazzaz, Fakhri a, Nona R Chiariello, Phyllis D Coley, and Louis F Pitelka. 1987. “Allocating Resources to Reproduction and Defense." BioScience 37 (1): 58-67. doi:10.2307/1310178.

Bisang, Irene, Johan Ehrlén, and Lars Hedenäs. 2006. "Reproductive Effort and Cost of Reproduction Do Not Explain Female-Biased Sex Ratios in the Moss Pseudocalliergon Trifarium (Amblystegiaceae)." American Journal of Botany 93 (9): 1313-19.

Bisang, Irene, and Lars Hedenäs. 2005. "Sex Ratio Patterns in Dioicous Bryophytes ReVisited.” Journal of Bryology 27 (3): 207-19. doi:10.1179/174328205X69959.

Bishop, JG. 2002. "Early Primary Succession on Mount St. Helens: Impact of Insect Herbivores on Colonizing Lupines." Ecology 83 (1): 191-202.

Bishop, John G, Niamh B O'Hara, Jonathan H Titus, Jennifer L Apple, Richard a Gill, and Louise Wynn. 2010. "N-P Co-Limitation of Primary Production and Response of Arthropods to N and P in Early Primary Succession on Mount St. Helens Volcano.” PloS One 5 (10): e13598. doi:10.1371/journal.pone.0013598.

Bowker, Matthew A., Lloyd R. Stark, D Nicholas McLetchie, and Brent Mishler. 2000. "Sex Expression, Skewed Sex Ratios, and Microhabitat Distribution in the Dioecious Desert Moss Syntrichia Caninervis (Pattiaceae)." American Journal of Botany 87 (4): 517-26.

Buck, William R, and Bernard Goffinet. 2000. "Morphology and Classification of Mosses.” In Bryophyte Biology, 71-123. doi:10.2307/3558438.

Budke, Jessica M., Bernard Goffinet, and Cynthia S. Jones. 2013. "Dehydration Protection Provided by a Maternal Cuticle Improves Offspring Fitness in the Moss Funaria Hygrometrica." Annals of Botany 111 (5): 781-89. doi:10.1093/aob/mct033.

Callaway, Ragan M., and Lawrence R. Walker. 1997. "Competition and Facilitation: A Synthetic Approach to Interactions in Plant Communities.” Ecology 78 (7): 195865. 
Casper, Brenda B, and Robert B Jackson. 1997. "Plant Competition." Nature 337 (6203): 122-23. doi:10.1146/annurev.ecolsys.28.1.545.

Chapin, F. S., Lawrence R. Walker, C. L. Fastie, and L. C. Sharman. 1994. "Mechanisms of Primary Succession Following Deglaciation at Glacier Bay , Alaska.” Ecological Monographs 64 (2): 149-75.

Chapin, Fs, K Autumn, and F Pugmaire. 1993. "Evolution of Suites of Traits in Response to Environmental Stress." The American Naturalist 142 (Supplement): S78-92.

Clements, Frederic E. 1916. Plant Succession. Carnegie Institution of Washington.

Coleman, David C., D.A. Crossley, and Paul F. Hendrix. 2004. "Fundamentals of Soil Ecology." Fundamentals of Soil Ecology, 271-98. doi:10.1016/B978-0121797263/50009-5.

Connell, Joseph H, and Ralph O Slatyer. 1977. "Mechanisms of Succession in Natural Communities and Their Role in Community Stability and Organization." The American Naturalist 111 (982): 1119-44.

Cornelissen, J. H. C., S. I. Lang, N. a. Soudzilovskaia, and H. J. During. 2007. "Comparative Cryptogam Ecology: A Review of Bryophyte and Lichen Traits That Drive Biogeochemistry." Annals of Botany 99 (5): 987-1001. doi:10.1093/aob/mcm030.

Cornelissen, J. H. C., S. Lavorel, E. Garnier, S. Díaz, N. Buchmann, D. E. Gurvich, P. B. Reich, et al. 2003. "A Handbook of Protocols for Standardised and Easy Measurement of Plant Functional Traits Worldwide." Australian Journal of Botany 51 (4): 335. doi:10.1071/BT02124.

Courtice, G R M, Neil W Ashton, and David J Cove. 1978. "Evidence for the Restricted Passage of Metabolites into the Sporophyte of the Moss Physcomitrella Patens (Hedw.) Br. Eur.” Journal of Bryology 2: 191-98. doi:10.1179/jbr.1978.10.2.191.

Cowles, Henry C. 1911. "The Causes of Vegetational Cycles." Annals of the Association of American Geographers 1 (1911): 3-20.

Cowles, Henry Chandler. 1899. The Ecological Relations of the Vegetation of the Sand Dunes of Lake Michigan. The University of Chicago.

Craine, J.M. 2009. "Resource Strategies of Wild Plants."

Delach, Aimee, and Robin Wall Kimmerer. 2002. "The Effect of Polytrichum Piliferum on Seed Germination and Establishment on Iron Mine Tailings in New York." The Bryologist 105 (2): 249-55.

del Moral, R, and D M Wood. 1993. "Early Primary Succession on the Volcano Mount St. Helen.” Journal of Vegetation Science 4 (2): 223-34.

del Moral, Roger, Lindsay a. Thomason, Anthony C. Wenke, Natasha Lozanoff, and Mario D. Abata. 2012. "Primary Succession Trajectories on Pumice at Mount St. Helens, Washington.” Edited by Beverly Collins. Journal of Vegetation Science 23 (1): 73-85. doi:10.1111/j.1654-1103.2011.01336.x.

Delgadillo, C, and A Cardenas. 1995. "Observations on Moss Succession on Paricutin Volcano, Mexico.” Bryologist 98: 606-8.

DeLuca, TH, O Zackrisson, MC Nilsson, and A Selistedt. 2002. "Quantifying NitrogenFixation in Feather Moss Carpets of Boreal Forests." Nature 419 (October): 917-19. doi:10.1038/nature01136.1. 
DeLuca, Thomas H., Olle Zackrisson, Francesco Gentili, Anita Sellstedt, and Marie Charlotte Nilsson. 2007. "Ecosystem Controls on Nitrogen Fixation in Boreal Feather Moss Communities." Oecologia 152: 121-30. doi:10.1007/s00442-0060626-6.

Egerton, Frank N. 2007. "A History of the Ecological Sciences, Part 23: Linnaeus and the Economy of Nature." Bulletin of the Ecological Society of America 88 (1): 72-88. doi:10.1890/0012-9623-91.1.21.

Ehrlén, Johan, Irène Bisang, and Lars Hedenäs. 2000. "Costs of Sporophyte Production in the Moss, Dicranum Polysetum." Plant Ecology 149 (2): 207-17. doi:10.1023/A:1026531122302.

Elbert, Wolfgang, Bettina Weber, Susannah Burrows, Jörg Steinkamp, Burkhard Büdel, Meinrat O. Andreae, and Ulrich Pöschl. 2012. "Contribution of Cryptogamic Covers to the Global Cycles of Carbon and Nitrogen." Nature Geoscience 5 (7). Nature Publishing Group: 459-62. doi:10.1038/ngeo1486.

Elliott, Carl W., Dylan G. Fischer, and Carri J. LeRoy. 2011. "Germination of Three Native Lupinus Species Un Response to Temperature." Field and Ecosystem Ecology 85 (2): 403-10. doi:10.3955/046.085.0223.

Endo, Elliot, Stephen Malone, Linda Noson, and Craig Weaver. 1981. "Locations, Magnitudes, and Statistics of the March 20-May 18 Earthquake Sequence." In The 1980 Eruptions of Mount St. Helens, Washington, 93-108.

Eppley, Sarah M., Todd N. Rosenstiel, Camille B. Graves, and Estefanía Llaneza García. 2011. "Limits to Sexual Reproduction in Geothermal Bryophytes." International Journal of Plant Sciences 172 (7): 870-78. doi:10.1086/660884.

Firbank, L G, and A R Watkinson. 1990. "On the Effects of Competition: From Monocultures to Mixtures." Perspectives on Plant Competition, 165-91.

Fryer, Janet L. 2008. "Polytrichum Juniperinum." Fire Effects Information System.

Gleason, Allan. 1917. "The Structure and Development of the Plant Association." Bulletin of the Torrey Botanical Society 44 (10): 463-81. doi:10.2307/2479596.

Gleason, H.A. 1939. "The Individualistic Concept of the Plant Association." The American Midland Naturalist 21 (1): 92-110.

Glime, J. M. 2015. "Ecophysiology of Development: Spore Germination.” In Bryophyte Ecology.

Glime, Janice M, and Irene Bisang. 2014a. "Sexuality: Reproductive Barriers and Tradeoffs." In Bryophyte Ecology, 1:1-30.

- 2014b. "Sexuality: Sex Ratio and Sex Expression." In Bryophyte Ecology, 1:130.

Goldberg, Deborah E. 1990. "Components of Resource Competition in Plant Communities.” In Perspectives on Plant Competition, 27-49. doi:10.1016/B978-012-294452-9.50007-2.

Gornall, Jemma L., Sarah J. Woodin, Ingibjorg S. Jónsdóttir, and R. van der Wal. 2011. "Balancing Positive and Negative Plant Interactions: How Mosses Structure Vascular Plant Communities." Oecologia 166: 769-82. doi:10.1007/s00442-0111911-6.

Grime, J. P. 1981. "Plant Strategies and Vegetation Processes." Agro-Ecosystems. doi:10.1016/0304-3746(81)90020-2. 
Grime, J P. 1977. "Evidence for the Existence of Three Primary Strategies in Plants and Its Relevance to Ecological and Evolutionary Theory." The American Naturalist 111 (982): 1169-94. doi: $10.2307 / 2460262$.

Hedderson, Terry a., and R. E. Longton. 2008. "Local Adaptation in Moss Life Histories: Population-Level Variation and a Reciprocal Transplant Experiment." Journal of Bryology 30 (1): 1-11. doi:10.1179/174328208X282175.

Hermans, Christian, John P. Hammond, Philip J. White, and Nathalie Verbruggen. 2006. "How Do Plants Respond to Nutrient Shortage by Biomass Allocation?" Trends in Plant Science. doi:10.1016/j.tplants.2006.10.007.

Hiltbrunner, Erika, Rien Aerts, Tobias Bühlmann, Kerstin Huss-Danell, Borgthor Magnusson, David D Myrold, Sasha C Reed, Bjarni D Sigurdsson, and Christian Körner. 2014. "Ecological Consequences of the Expansion of $\mathrm{N}_{2}$-Fixing Plants in Cold Biomes." Oecologia 176 (1): 11-24. doi:10.1007/s00442-014-2991-x.

Kato-Noguchi, H., K. Kobayashi, and H. Shigemori. 2009. "Allelopathy of the Moss Hypnum Plumaeforme by the Production of Momilactone A and B." Weed Research 49: 621-27. doi:10.1111/j.1365-3180.2009.00731.x.

Kato-Noguchi, Hisashi, Takahiro Seki, and Hideyuki Shigemori. 2010. "Allelopathy and Allelopathic Substance in the Moss Rhynchostegium Pallidifolium." Journal of Plant Physiology 167 (6). Elsevier: 468-71. doi:10.1016/j.jplph.2009.10.018.

Kleyer, M., R. M. Bekker, I. C. Knevel, J. P. Bakker, K. Thompson, M. Sonnenschein, P. Poschlod, et al. 2008. "The LEDA Traitbase: A Database of Life-History Traits of the Northwest European Flora." Journal of Ecology 96 (6): 1266-74. doi:10.1111/j.1365-2745.2008.01430.x.

Lang, Frank Alexander. 1961. "A Study of Vegetation Change on the Gravelly Prairies of Pierce and Thurston Counties, Western Washington." University of Washington.

Ligrone, Roberto, Jeffrey G. Duckett, and Karen S. Renzaglia. 2012. "The Origin of the Sporophyte Shoot in Land Plants: A Bryological Perspective." Annals of Botany. doi:10.1093/aob/mcs176.

Linhart, Yan B., and Michael C. Grant. 1996. "Evolutionary Significance of Local Genetic Differentiation in Plants\n." Annual Review of Ecology and Systematics 27 (1): 237-77. doi:10.1146/annurev.ecolsys.27.1.237.

McDowell, Nate, William T Pockman, Craig D Allen, David D Breshears, Neil Cobb, Thomas Kolb, Jennifer Plaut, et al. 2008. "Mechanisms of Plant Survival and Mortality during Drought: Why Do Some Plants Survive While Others Succumb to Drought?" The New Phytologist 178 (4): 719-39. doi:10.1111/j.14698137.2008.02436.x.

Meagher, TR. 1988. "Sex Determination in Plants." In Plant Reproductive Ecology, 12553.

Meiners, Scott J., Chui Hua Kong, Laura M. Ladwig, Nikki L. Pisula, and Kimberly A. Lang. 2013. "Developing an Ecological Context for Allelopathy." Plant Ecology 213 (12): 1861-67. doi:10.1007/s11258-012-0121-6.

Michalet, Richard, Sa Xiao, Blaise Touzard, David S Smith, Lohengrin a Cavieres, Ragan M Callaway, and Thomas G Whitham. 2011. "Phenotypic Variation in Nurse Traits and Community Feedbacks Define an Alpine Community." Ecology Letters 14 (5): 433-43. doi:10.1111/j.1461-0248.2011.01605.x. 
Michel, Pascale, David J. Burritt, and William G. Lee. 2011. "Bryophytes Display Allelopathic Interactions with Tree Species in Native Forest Ecosystems." Oikos 120 (8): 1272-80. doi:10.1111/j.1600-0706.2010.19148.x.

Mishler, Brent D. 1988. "Reproductive Ecology of Bryophytes." In Plant Reproductive Ecology, edited by Jon Doust and Lesley Doust, 285-306. New York: Oxford University Press.

Mishler, Brent, and Angela Newton. 1988. "Influences of Mature Plants and Desiccation on Germination of Spores and Gametophytic Fragments on Tortula." Journal of Bryology 15: 327-42.

Mishler, Brent, and Melvin J Oliver. 1991. "Gametophytic Phenology of Tortula Ruralis , a Desiccation-Tolerant Moss, in the Organ Mountains of Southern New Mexico." The Bryologist 94 (2): 143-53.

Morran, Levi T., Brian J. Cappy, Jennifer L. Anderson, and Patrick C. Phillips. 2009. "Sexual Partners for the Stressed: Facultative Outcrossing in the Self-Fertilizing Nematode Caenorhabditis Elegans." Evolution 63 (6): 1473-82. doi:10.1111/j.15585646.2009.00652.x.

Nilsson, Marie-Charlotte, Ingeborg Steijlen, and Olle Zackrisson. 1996. "Time-Restricted Seed Regeneration of Scots Pine in Sites Dominated by Feather Moss after ClearCutting." Canadian Journal of Forest Research 26 (6): 945-53. doi:10.1139/x26104.

Norrell, Tatum E, Kelly S Jones, Adam C Payton, and Stuart F McDaniel. 2014. "Meiotic Sex Ratio Variation in Natural Populations of Ceratodon Purpureus (Ditrichaceae)." American Journal of Botany 101 (9): 1572-76. doi:10.3732/ajb.1400156.

Odum, Eugene P. 1969. "The Strategy of Ecosystem Development.” Science 164 (3877): 262-70.

Oechel, W C, and K Van Cleve. 1986. "The Role of Bryophytes in Nutrient Cycling in the Taiga." In Forest Ecosystems in the Alaskan Taiga, 57:121-37.

Proctor, Michael C. F. 2000. "Physiological Ecology." In Bryophyte Biology, edited by A. Jonathan Shaw and Bernard Goffinet, 225-47. Cambridge: Cambridge University Press.

Proctor, Michael C. F., Melvin J. Oliver, Andrew J. Wood, Peter Alpert, Lloyd R. Stark, Natalie L. Cleavitt, and Brent D. Mishler. 2007. "Desiccation-Tolerance in Bryophytes: A Review.” The Bryologist 110 (4): 595-621. doi:10.1639/00072745(2007)110[595:DIBAR]2.0.CO;2.

Rejmanek, Marcel, Radka Haagerova, and Jiri Haager. 1982. "Progress of Plant Succession on the Paricutin Volcano :25 Years after Activity Ceased." American Midland Naturalist 108 (1): 194-98.

Reznick, David. 1985. "Costs of Reproduction: An Evaluation of the Empirical Evidence." Oikos 44: 257-67. doi:10.2307/3544698.

Rydgren, K, and R H Okland. 2003. "Short-Term Costs of Sexual Reproduction in the Clonal Moss Hylocomium Splendens.” Bryologist 106 (2): 212-20. doi:10.1639/0007-2745(2003)106[0212:SCOSRI]2.0.CO;2.

Santamaría, Luis. 2002. "Why Are Most Aquatic Plants Widely Distributed? Dispersal, Clonal Growth and Small-Scale Heterogeneity in a Stressful Environment." Acta Oecologica 23 (3): 137-54. doi:10.1016/S1146-609X(02)01146-3. 
Schmidt, S K, Sasha C Reed, Diana R Nemergut, a Stuart Grandy, Cory C Cleveland, Michael N Weintraub, Andrew W Hill, et al. 2008. "The Earliest Stages of Ecosystem Succession in High-Elevation (5000 Metres above Sea Level), Recently Deglaciated Soils." Proceedings. Biological Sciences / The Royal Society 275 (1653): 2793-2802. doi:10.1098/rspb.2008.0808.

Schoenfelder, Anna C, John G Bishop, Holly M Martinson, and William F Fagan. 2010. "Resource Use Efficiency and Community Effects of Invasive Hypochaeris Radicata (Asteraceae) during Primary Succession.” American Journal of Botany 97 (11): 1772-79. doi:10.3732/ajb.0900383.

Shinozaki, K, and T Kira. 1956. "Intraspecific Competition among Higher Plants. VII. Logistic Theory of the C-D Effect." J. Inst. Polytech. Osaka Cy. Univ. D. 7: 35-72 ST-Intraspecific competition among higher.

Smith, Gary L. 1971. "A Conspectus of the Genera of Polytrichaceae." Memoirs of the New York Botanical Garden 21 (3): 1-83.

Smith, Robert J., and Lloyd R. Stark. 2014. "Habitat vs. Dispersal Constraints on Bryophyte Diversity in the Mojave Desert, USA." Journal of Arid Environments 102 (March). Elsevier Ltd: 76-81. doi:10.1016/j.jaridenv.2013.11.011.

Sorbo, Sergio, Adriana Basile, and Rosa Castaldo Cobianchi. 2004. "Antibacterial, Antioxidant and Allelopathic Activities in Bryophytes." Recent Research Developments in Phytochemistry 8: 69-82.

Sousa, Wayne P. 1984. "The Role of Disturbance in Natural Communities." Annual Review of Ecology \& Systematics, no. 15: 353-91.

Sparrius, Laurens B., and Annemieke M. Kooijman. 2013. "Nitrogen Deposition and Soil Carbon Content Affect Nitrogen Mineralization during Primary Succession in Acid Inland Drift Sand Vegetation." Plant and Soil 364 (1-2): 219-28. doi:10.1007/s11104-012-1351-z.

St. John, Mark G., Peter J. Bellingham, Lawrence R. Walker, Kate H. Orwin, Karen I. Bonner, Ian a. Dickie, Chris W. Morse, Gregor W. Yeates, and David a. Wardle. 2012. "Loss of a Dominant Nitrogen-Fixing Shrub in Primary Succession: Consequences for Plant and below-Ground Communities." Edited by Amy Austin. Journal of Ecology 100 (5): 1074-84. doi:10.1111/j.1365-2745.2012.02000.x.

Stark, Lloyd R. 2005. "Phenology of Patch Hydration, Patch Temperature and Sexual Reproductive Output over a Four-Year Period in the Desert Moss Crossidium Crassinerve." Journal of Bryology 27 (3): 231-40. doi:10.1179/174328205X69977.

Stark, Lloyd R., Brent Mishler, and D. Nicholas McLetchie. 2000. "The Cost of Realized Sexual Reproduction: Assessing Patterns of Reproductive Allocation and Sporophyte Abortion in a Desert Moss." American Journal of Botany 87 (11): 15991608.

Stark, Lloyd R, John C Brinda, and D Nicholas McLetchie. 2009. “An Experimental Demonstration of the Cost of Sex and a Potential Resource Limitation on Reproduction in the Moss Pterygoneurum (Pottiaceae)." American Journal of Botany 96 (9): 1712-21. doi:10.3732/ajb.0900084.

Stearns, S C. 1989. “Trade-Offs in Life-History Evolution.” Functional Ecology 3 (3): 259-68.

Stearns, SC. 1976. "Life-History Tactics: A Review of the Ideas." The Quarterly Review of Biology 51 (1): 3-47. 
Steen Mogensen, Gert. 1981. "The Biological Significance of Morphological Characters in Bryophytes : The Spore." The Bryologist 84 (2): 187-207.

Stephenson, A.G. 1981. "Flower and Fruit Abortion: Procimate Causes and Ultimate Functions." Annual Review of Ecology \& Systematics, no. 12: 253-79.

Talbot, Stephen S., Sandra Looman Talbot, and Lawrence R. Walker. 2010. "PostEruption Legacy Effects and Their Implications for Long-Term Recovery of the Vegetation on Kasatochi Island, Alaska." Arctic, Antarctic, and Alpine Research 42 (3): 285-96. doi:10.1657/1938-4246-42.3.285.

Thomas, RJ, and CS Lombard. 1991. "Aphid Infestation and Its Effects on Translocation in Polytrichum Commune." The Bryologist 94 (1): 1-4.

Tilling, Robert I, Lyn Topinka, and Donald A Swanson. 2002. Eruptions of Mount St. Helens: Past, Present and Future. US Geological Survey.

Titus, Jonathan H. 2009. "Nitrogen-Fixers Alnus and Lupinus Influence Soil Characteristics but Not Colonization by Later Successional Species in Primary Succession on Mount St. Helens." Plant Ecology 203 (2): 289-301. doi:10.1007/s11258-008-9549-0.

Titus, Jonathan H., and John G. Bishop. 2014. "Propagule Limitation and Competition with Nitrogen Fixers Limit Conifer Colonization during Primary Succession." Edited by Roger del Moral. Journal of Vegetation Science, January, 1-14. doi:10.1111/jvs.12155.

Turetsky, Merritt R. 2003. "The Role of Bryophytes in Carbon and Nitrogen Cycling." Bryologist 106 (3): 395-409.

Turetsky, Merritt R., Michelle C. Mack, Teresa N. Hollingsworth, and Jennifer W. Harden. 2010. "The Role of Mosses in Ecosystem Succession and Function in Alaska's Boreal Forest." Canadian Journal of Forest Research 40: 1237-64. doi:10.1139/X10-072.

Tveten, R. K.; Fonda, R. W. 1999. "Fire Effects on Prairies and Oak Woodlands on Fort Lewis, Washington." Northwest Science 73 (3): 145-58.

Vincent, C D, A J Lawlor, and E Tipping. 2001. "Accumulation of Al, Mn , Fe , Cu , Zn , $\mathrm{Cd}$ and $\mathrm{Pb}$ by the Bryophyte Scapania Undulata in Three Upland Waters of Di Erent pH" 114: 93-100.

Violle, Cyrille, Helena Castro, Jean Richarte, and Marie Laure Navas. 2009. "Intraspecific Seed Trait Variations and Competition: Passive or Adaptive Response?" Functional Ecology 23 (3): 612-20. doi:10.1111/j.13652435.2009.01539.x.

Vitousek, Peter M., Carla M D’Antonio, Lloyd L. Loope, Marcel Rejmanek, and Randy Westbrooks. 1997. "Introduced Speces: A Significant Component of Human-Caused Global Environmental Change." New Zealand Journal of Ecology 21 (1): 1-16.

Vitousek, Peter M, Keith Van Cleve, Nadarajah Balakrishnan, and Dieter MuellerDombois. 1983. "Soil Development and Nitrogen Turnover in Montane Rainforest Soils on Hawai ' I." Biotropica 15 (4): 268-74.

Weinig, C. 2000. "Differing Selection in Alternative Competitive Environments: ShadeAvoidance Responses and Germination Timing." Evolution 54 (1): 124-36. doi: $10.2307 / 2640479$. 
Weir, Tiffany L., Sang Wook Park, and Jorge M. Vivanco. 2004. "Biochemical and Physiological Mechanisms Mediated by Allelochemicals." Current Opinion in Plant Biology 7 (4): 472-79. doi:10.1016/j.pbi.2004.05.007.

Williamson, G B. 1990. “Allelopathy, Koch's Postulates, and the Neck Riddle.” Perspectives on Plant Competition., 143-62.

Wood, David, and Roger del Moral. 1987. "Mechanisms of Early Primary Succession in Subalpine Habitats on Mount St . Helens." Ecology 68 (4): 780-90.

Worster, Donald. 1977. Nature's Economy: A History of Ecological Ideas. San Francisco: Sierra Club Books.

Wuermli, M. 1976. "Plant and Animal Settlements in Recent Lavas and Ashes from Mount Etna with Special Emphasis on Structural Aspects." In Session Report. Work Group 1, Biology, Minerology, Geology and Related Sciences., 185:135-228.

Yelenik, Stephanie G, and Carla M D'Antonio. 2013. "Self-Reinforcing Impacts of Plant Invasions Change over Time.” Nature 503 (7477). Nature Publishing Group: 51720. doi:10.1038/nature12798.

Zartman, Charles E., July A. Amaral, Jos?? N. Figueiredo, and Cristian de Sales Dambros. 2015. "Drought Impacts Survivorship and Reproductive Strategies of an Epiphyllous Leafy Liverwort in Central Amazonia.” Biotropica 47 (2): 172-78. doi:10.1111/btp.12201. 